\title{
Not when but if: Modality and future time reference in English, Dutch and German
}

\author{
Cole Robertson $^{1 *}$, Seán G. Roberts ${ }^{2}$
}

August 19, 2020

\footnotetext{
${ }^{1}$ University of Oxford, Department of Experimental Psychology, Radcliffe Observatory, Anna Watts Building, Woodstock Rd, Oxford OX2 6GG
}

\footnotetext{
${ }^{2}$ University of Bristol

${ }^{*}$ corresponding author
} 


\section{Abstract}

Recently, economists have used notions of linguistic relativity to suggest that grammatical constraints on Future Time Reference (FTR) affect whether people choose to take a small reward now or wait until later for a larger reward ("temporal discounting"). Economists hypothesize that habitual use of present tense constructions for FTR may cause speakers to perceive future rewards as temporally closer, and thereby as more valuable. This approach assumes that future tenses primarily encode when an event happens, which overlooks their widespread tendency to encode modal notions of probability. It additionally overlooks the importance of modal expressions in FTR. Since people discount value as a function of both temporal distance and the probability of a reward being received, it is important to understand what different FTR tenses actually encode, as well as cross-linguistic differences in the grammaticization of modality. We therefore modified the EUROTYP questionnaire to elicit future tense as well as modal FTR constructions across a range of temporal distances and probabilities for speakers of English, Dutch, and German. We find that in English tense and probability are more strictly grammaticized than in Dutch or German, and that increasing temporal distance from speaker "now" tended to cause English and German - but not Dutch - speakers to use more uncertain terms. These results highlight the importance of modality for typological linguists working on FTR, and suggest economists working on linguistic relativity and psychological discounting should consider cross-linguistic differences in the grammaticization of modality and in the modal semantics of future tenses. 


\section{Introduction}

Do differences between languages change the way people think, feel, and act? The linguistic relativity hypothesis suggests that they do (Whorf, 1956). The idea is that languages demand speakers notice different things in order to communicate, and that the resultant differences in online attentional demands grow through lifelong language use into entrenched offline cognitive differences. For instance, when choosing between the English demonstratives this and that, speakers need only pay attention to whether the referred-to object is located near or far from themselves. Spanish breaks this space into three degrees of distance (i.e. near, far, and very far), and Malagasy breaks it into seven (Evans, Bergqvist, \& San Roque, 2018). Might these more granular gradations cause speakers of Spanish or Malagasy to be faster or more precise at estimating distance? A growing body of research suggests this is likely (for review, see: Boroditsky, 2006, Wolff \& Holmes, 2011, Majid, 2018.

A typical way linguistic relativity research progresses is by identifying prospective typological differences and then investigating whether they give rise to corollary cognitive effects (Lucy, 1997, 2016). Such an approach has recently been taken up by a growing number of economists who have sought to test whether cross-linguistic differences in the grammaticization of FTR [1] affect speakers' future orientation K. Chen, 2013 S. Chen, Cronqvist, Ni, \& Zhang, 2017, Chi, Su, Tang, \& Xu, 2018, Fasan, Gotti, Kang, \& Liu, 2016, Figlio, Giuliano, Özek, \& Sapienza, 2016, Galor, Özak, \& Sarid, 2016, Guin, 2017, Hübner \& Vannoorenberghe, 2015a, Karapandza, 2016 Kim, Kim, \& Zhou, 2017, Liang, Marquis, Renneboog, \& Sun, 2018, ?, ?] Mavisakalyan \& Weber, 2018, Mavisakalyan, Tarverdi, \& Weber, 2018, Pérez \& Tavits, 2017; Roberts, Winters, \& Chen, 2015; Sutter, Angerer, Glätzle-rützler, \& Lergetporer, 2015. Thoma \& Tytus, 2018). The suggestion is that speakers of languages with strict future tenses might be less future-orientated because increased grammatical marking of FTR would cause them to discount value as a function of time to a greater degree than do speakers of languages which do not mark FTR K. Chen, 2013). However, there may be critical shortcomings in the widely-employed typology on which this research is based (K. Chen, 2013), at least for the purposes to which it has been put. We argue this

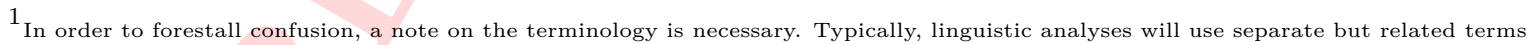
for notional categories and the linguistic structures which grammatically encode them (Bybee, Perkins, \& Pagliuca 1994. We will follow the literature in using FTR to denote any statement which involves reference to future events and "future tense" to denote the linguistic structures which sometimes grammatically mark FTR, e.g. in English will, shall, or be going to. Since we are generally interested in understanding the impact of differences in FTR grammaticization on cognition, we will take the notional domain as the starting point and explore the extent to which obligatory grammatically marking may impact upon cognition (for more on this approach, see: Nuyts 2000.
} 
is principally because it does not include any treatment of cross-linguistic differences in modality ${ }^{2}$

This is problematic for three reasons. Firstly, the perceived probability of an event occurring has been found to impact subjective estimations of value as much or more than temporal delay (Białaszek, Ostaszewski, Green, \& Myerson, 2019, Green, Myerson, \& Ostaszewski, 1999, Green \& Myerson, 2004. Rachlin, Raineri, \& Cross, 1991). Secondly, there is a robust typological tendency for future tenses to encode modal notions of probability (Broekhuis \& Verkuyl, 2014; Bybee et al., 1994; Enç, 1996, Fries, 2006: Giannakidou, 2014, Giannakidou \& Mari, 2018; Huddleston, 1995, Nuyts \& Vonk, 1999, Sarkar, 1998). Thirdly, modal grams ${ }^{3}$ are a cross-linguistically common FTR structure, and allow speakers to encode degrees of epistemic commitment to future events, e.g. "it could rain", Nuyts, 2000, Palmer, 2001). In other words, modality and tense tend to overlap in FTR, and both domains impact subjective estimations of value. Research which isolates only one of these factors (time) may be producing biased results due to unmeasured confounding variables (probability).

The binary typology underpinning most research to date as formulated in K. Chen (2013), was largely based on the EUROTYP project (Dahl, 1985, 2000), a typological exploration of tense and aspect systems in European languages. However, despite the seminal contribution of EUROTYP to FTR typology, the project did not include any treatment of modality; among other things, this has given rise to criticisms of the typology given by K . Chen (2013) for failing to adequately capture the cross-linguistic complexities of FTR (Dahl, 2013, Liberman, 2012, Pereltsvaig, 2011, Pullum, 2012). However, as far as we know there does not exist a quantitative typology of modality which would allow for it to be included as a statistical control in the large-scale regression-based analyses which have mostly characterized research to date. Additionally, it does not appear to be known whether the grammaticization of FTR and modality tend to be cross-linguistically correlated, so the extent of potential confounding is unclear.

This paper will therefore present the results of an updated version of the elicitation questionnaire used by EUROTYP, which also includes new questions to specifically elicit modal constructions. We will first summarize the hypothesis that FTR grammaticization might affect future-orientation $\mathrm{K}$. Chen. 2013). Following this, we present the case that the FUTURE TENSE and EPISTEMIC MODALITY ${ }^{4}$ are too closely related to be investigated in isolation. This will be discussed with reference to the languages

\footnotetext{
2 As with FTR and tense we use modality to denote the notional domain, while mood will denote the inflectional marking of this domain in some languages (Bybee et al. 1994).

3 "Gram" denotes language-specific structures which variously exemplify general cross-linguistic categories like tense and modality.

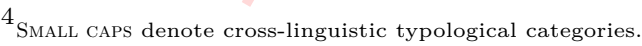


in our sample, which will be English, Dutch and German. While partly a sample of convenience, two of these languages (Dutch and German) do not strictly grammaticize FTR, while English does (Dahl, 2000). Additionally, the fact that English may also more strictly grammaticize modality makes these three languages suitable for exploration of the relationship between the grammaticization of time and modality (Nuyts, 2000). Finally, they are all drawn from the same Western Germanic language family, which facilitates easier comparison.

\subsection{The FTR and temporal discounting hypothesis}

The hypothesis that FTR grammaticization could affect future-orientation is based on two observations. Firstly, people tend to discount value as a function of temporal distance (Green \& Myerson, 2004, Rachlin et al. 1991). Ask most people whether they would prefer $\$ 100$ now or $\$ 100$ in a year, and they will nearly invariably choose the first option, but offer them $\$ 10,000$ in a year's time and most will prefer the second (Green \& Myerson, 2004). The shape of this discounting function has been found to affect a range of important intertemporal decisions, such as propensity to substance addiction (smoking, heroin, alcohol), health-related lifestyle choices, and savings behavior Angeletos, Laibson, Repetto, Tobacman, \& Weinberg, 2001; Green \& Myerson, 2004, McKerchar \& Renda, 2012, Vuchinich \& Simpson, 1998).

Secondly, not all languages force speakers to grammatically mark FTR (K. Chen, 2013, Dahl, 2000):

(1) English: It will rain tomorrow.

$$
\text { Morgen regn-et es. }
$$

(2) German: Tomorrow rains-PRESENT it

'Tomorrow it rains.'

In English (1) it is necessary to use will, be going to, or shall (rare) constructions in most FTR sentences (Dahl, 2000). No such restrictions exist in German or Dutch, where constructions like (2) are acceptable. K. Chen (2013) classifies languages into two categories: languages like German with less strict or no FTR grammaticization, and languages like English with strict FTR grammaticization. These are termed "weak-FTR" and "strong-FTR", respectively, and K. Chen (2013) hypothesizes that speakers of weakFTR languages will tend to discount less than speakers of strong-FTR languages, which would mean they would tend to be more patient, healthier, and save more for retirement $\mathrm{K}$. Chen, 2013). 
Two mechanisms are suggested to mediate a relationship between FTR grammaticization and temporal discounting; both involve differences in underlying beliefs about the temporal "location" of future events K. Chen, 2013). The first is that speakers of weak-FTR languages might, through repeated use of the present tense for FTR, come to perceive the future as being more temporally proximal than speakers of strong-FTR languages. Given typical human discounting curves, they would then tend to overestimate value and cost compared to speakers of strong-FTR languages, Fig. 1] The second mechanism is that weak-FTR languages might not mandate that speakers think as precisely about the temporal location of future events, which would result in higher estimations of future values and costs, see Fig. 2 Since proposed in K. Chen (2013), a growing number of studies have used the weak versus strong typology in large-scale statistical analyses, and found it to predict various behaviors related to temporal discounting, including accounting practices, savings management, educational outcomes, health related lifestyle choices, safe sex practices, and support for future-orientated environmental policy (c.f. K. Chen, 2013; Hübner \& Vannoorenberghe, 2015a, 2015b, Mavisakalyan et al., 2018; Fasan et al., 2016; S. Chen, Cronqvist, Ni, \& Zhang, 2015; Sutter et al., 2015; Figlio et al., 2016, Kim et al., 2017; Karapandza, 2016; Guin, 2017, Liang et al. 2018, ?, S. Chen et al. 2017).

However, in real world decision making, people have to balance temporal distance with probability. Someone deciding to smoke a cigarette must balance the immediate reward of smoking against her estimation of the costs as a function of both the delay and the probability of paying them, i.e. when and if she will develop smoking-related health problems. In fact, probability has been found to be as important a factor as temporal distance in driving subjective estimations of value (Baucells \& Heukamp, 2010, 2012; Białaszek et al. 2019, Du, Green, \& Myerson, 2002; Green et al., 1999, Green \& Myerson, 2004 Green, Myerson, \& Vanderveldt, 2014, McKerchar \& Renda, 2012, Rachlin et al., 1991, Vanderveldt, Green, \& Myerson, 2015, Yi, de la Piedad, \& Bickel, 2006), these dimensions have been found to interact multiplicatively (Vanderveldt et al., 2015, Vanderveldt, Green, \& Rachlin, 2017), and models which combine these factors have been found to fit empirical results better than models which isolate them (Luckman, Donkin, \& Newell, 2018). Realistic models of psychological discounting should therefore incorporate not just delay and probability but also their conditional effect on discounting. However, to our knowledge, there have not been any studies which have sought to characterize how the grammaticization of modality and FTR interact to impact upon psychological discounting. This paper paves the way for 
this sort of investigation by first examining the usage differences between English, Dutch, and German speakers with a view to characterizing the cross-linguistic differences in modality and FTR likely to affect psychological discounting processes; we hope that such typological criteria may be used in future studies which explicitly investigate psychological discounting.

\subsection{The grammaticization of modality and psychological dis-}

\section{counting}

We suggest there are two critical ways in which cross-linguistic differences in the grammaticization of modality are likely to impact upon psychological discounting. Firstly, the literature reveals a robust typological tendency for future tense grams to encode modal notions of probability, so it is possible that some reported effects of "weak-" vs. strong-FTR are due to cross-linguistic differences in the modal constituents of future tense grams (Broekhuis \& Verkuyl, 2014, Bybee \& Dahl, 1989, Enç, 1996. Fries, 2006, Huddleston, 1995, Janssen, 1989, Kirsner, 1969, Kissine, 2008, Sarkar, 1998, Salkie, 2010). Secondly, modal grams are an important way of expressing gradations of probability vis-à-vis future events, e.g. It may rain tomorrow (Bybee \& Dahl, 1989, Enç, 1996). It is reasonable to hypothesize that speakers of languages which strictly grammaticize modality might exhibit increased probabilistic discounting rates. We will deal with the first suggestion below with reference to will (English), zullen (Dutch), and werden (German) ${ }^{5}$ Following this, we will discuss differences between the modal systems in English, Dutch, and German.

\subsubsection{Will, zullen, and werden: tenses or modal verbs?}

A critical piece of evidence for the suggestion that will may tend to encode modal notions is its sensitivity to what we here term "FTR mode". FTR mode covers the contexts in which it is possible to refer to future events, these being 1) intentions, 2) predictions, and 3) schedules (Dahl, 2000). Will becomes increasingly obligatory across FTR-modes:

(4) His train arrives/is arriving/? will arrive at $6 \mathrm{pm}$.

\footnotetext{
5 The de andative FTR grams gaan and be going to are common in Dutch and English, but appear to be less frequent, Tables 24 and do not tend to encode modality to the same extent so will not be our focus here Dahl 2000
} 
(5) I arrive/am arriving/will arrive at $6 \mathrm{pm}$.

(6) John ?arrives/is arriving/will arrive at $6 \mathrm{pm}$.

(7) Dinner ?is ready/will be ready/ at $6 \mathrm{pm}$.

(8) The bomb ?explodes/? is exploding/will explode tonight 6

These sentences are syntactically similar, and all refer to the future; however, will becomes increasingly necessary changes from schedule, to intention, to prediction. Given that there is an epistemic cline across FTR mode from schedules (most certain) to predictions (least certain), it would seem that will tends to encode something to do with modality as well as time (Enç, 1996; Dahl, 2000; Huddleston, 1995, Fries, 2006). Such a conclusion is supported by the fact that, it is perfectly acceptable to use will to mark a prediction in present time contexts. For instance:

(9) That will be the postman.

(10) That is the postman.

Will in (9) marks a present time prediction, indicating that the semantics of will are not strictly temporal and rather that will tends to mark predictions regardless of the time frame (inter alia Enç, 1996 . Huddleston, 1995. Huddleston \& Pullum, 2002). For these and other reasons, most scholars agree that a purely temporal interpretation of will is inadequate, though the precise modal semantics of will is debated (Broekhuis \& Verkuyl, 2014, Dahl, 2000, Enç, 1996, Fries, 2006, Huddleston, 1995, Huddleston \& Pullum, 2002, Sarkar, 1998, Salkie, 2010).

The case for a modal interpretation of zullen, or indeed any future gram in weak-FTR languages, is compellingly presented by Broekhuis and Verkuyl (2014). They argue that since the Dutch present tense can be used to refer to a time span encompassing both before and after the time of speech, the contribution zullen must be purely modal (see also: Fehringer, 2018, Giannakidou, 2014). They give the following examples, wherein the uncontroversial modal auxiliaries of possibility, kunnen "may", and necessity, moeten "must", are contrasted with zullen "will":

(11) Dat huis op de hoek moet instorten.

"That house on the corner must collapse." 
(12) Dat huis op de hoek kan instorten.

"That house on the corner may collapse."

(13) Dat huis op de hoek zal instorten.

"That house on the corner will collapse."

According to Broekhuis and Verkuyl (2014) these examples are all compatible with a future reading, or, given concurrent evidence of a collapse actually occurring (i.e. rumbling, visible instability), they may refer to a present event (Broekhuis \& Verkuyl, 2014). If both present and future time interpretations are possible for zullen, they suggest that its primary contribution cannot be temporal and must be purely modal. Similar analysis also applies to the German "future" werden (Janssen, 1989).

However, as with will, the exact nature of the semantic contribution of zullen is difficult to pin down. Broekhuis and Verkuyl (2014) suggest it constitutes marking of an expected or "projected" future. It is our contention that the semantics of modal auxiliaries like zullen can only be understood when contrasted against the other epistemic modal construction types which are grammatically possible in a given language and in the same FTR mode. In the next section we therefore discuss cross-linguistic differences in the grammaticization of modality, before interpretations of the modal semantics of will, zullen, and werden in light of these, and suggesting some potential impacts upon psychological discounting.

\subsubsection{Epistemic modality in English, Dutch, and German}

Modal expressions are an important way of referring to the future, and typically involve a speaker expressing degrees of possibility, probability, and certainty relative to a "modal base" which can range from the rules and norms governing social interaction (deontic modality) to a person or object's inherent abilities (dynamic modality) (Palmer, 2001). Since it seems the most likely modal base to be implicated in psychological discounting processes, we are here most interested in epistemic modality, in which speakers express degrees of probability relative to what they know or believe (Palmer, 2001). English, Dutch, and German distribute the expression of epistemic modality across several shared word classes, these being: modal verbs (14), modal adverbs (15), predicative adjectives (16), nouns (17, rare), and mental state predicates (18) (Nuyts, 2000):

(14) It might/may/could/should rain tomorrow. 
(15) It will definitely/possibly rain tomorrow.

(16) It is probable/certain that it will rain tomorrow.

(17) It is a certainty/possibility that it will rain tomorrow.

(18) I think/believe/reckon it will rain tomorrow.

We follow Nuyts (2000) and treat predicative adjectives, nouns, and modal adverbs as one meta-type, as they often share roots, and derived forms encode only subtle semantic differences. We terms these "modal modifiers". Below we briefly discuss each construction types.

MODAL MODIFIERS: These may be thought of as the "purest" expressions of epistemic modality, as they allow for the most precise expression of epistemic modal notions, and tend to have well-defined semantics that are relatively stable across differing pragmatic contexts (Nuyts, 2000). The three languages break the modal scale into three approximately equivalent points: 1) high certainty, 2) moderate certainty, and 3) low certainty (50/50). In English these are indexed with certainly, probably, and possibly, respectively (Dutch and German systems are similar, see Tables 34 .

Mental state PREdicates: English, Dutch, and German share similar systems of epistemic mental state predicates. However, there are between-language differences. For instance, the prototypical examples in English are think, believe and sometimes guess (American) (Nuyts, 2000). In Dutch denken "think" is also prototypical, but the German cognate, denken, is rarely used epistemically, while glauben "believe" is more prototypical (Nuyts, 2000), and erwarten "expect" is the most frequent in our data, Table 4 Similarly to epistemic modal modifiers, epistemic mental state predicates index gradations between certainty and uncertainty; however, their exact position on this scale is somewhat less welldefined, i.e. the relative differences between believe, guess, suppose, and think (and Dutch and German equivalents), is unclear (Nuyts, 2000). Differing from the modal modifiers, it seems that there are no clear high-certainty mental state predicates.

MODAL VERBS: In these languages, the modal verbs for which epistemic use is possible are a subset of the more general set of modal verbs (Nuyts, 2000). Similarly to mental state predicates, epistemic modal verbs tend to express gradations of uncertainty rather than high-certainty. The main highcertainty modal verb, must/mussen/moeten, is mostly limited to deontic rather than epistemic modal bases. Apart from will, zullen and werden, which might be considered high-certainty, this leaves a set of 
modal verbs which tend to encode either probability or possibility. For instance may, might, and could encode possibility, while should encodes slightly stronger notions of probability (Nuyts, 2000). In Dutch, kunnen "may" is the only modal for which epistemic use is possible, and encodes possibility (Nuyts, 2000). The German case is complicated by the Konjunktiv II, a bound morphological subjunctive mood. While mostly used to express irrealis notions (Thieroff, 2010), the Konjunctive II can also attenuate German modal verbs, altering their modal polarity, or the modal base to which they can refer (Mortelmans, 2000. Nuyts, 2000). For instance, mögen "may" encodes possibility, but only in the present tense mag, while in the Konjunktiv II, möchte, it can only be used in deontic contexts (Nuyts, 2000). Conversely, dürfen "may" encodes probability in the Konjunktiv II, dürfte, but not in the present, darf, which is deontic, and Müssen "must", expresses probability in the Konjunctive II, müßte "should," but the present tense, muss, is deontic (Mortelmans, 2000). Finally, Können "may", expresses epistemic possibility in both the present, kan, and Konjunktiv II, könte, but the latter indicates a comparative weakening of commitment (Mortelmans, 2000). As in English and Dutch, when epistemic use is possible for a given inflectional verb form, it expresses probability (müßte, dürfte), or possibility mag, kan, könte) (Nuyts, 2000 Mortelmans, 2000 .

Additionally to these shared ways of expressing epistemic modality, Dutch and German also have systems of modal particles which can affect the modal strength of FTR statements, often subtly changing the modal valence of an expression when they co-occur with other modal morphemes (Fehringer, 2018. Nuyts, 2000). While a limited set of modal particles appear to independently epistemically affect statements (see Tables 3 4), we will not spend much time discussing these, as they appear to be a relatively minor way of expressing epistemic modality (Nuyts, 2000), and are generally more involved in marking the epistemic states of discourse participants, or expressing discourse attitudes (c.f. Bross, 2012 . Gutzmann, 2009; Hogeweg, Ramachers, \& Wottrich, 2011, Karagjosova, 2004, Zimmermann, 2019.

\subsubsection{Implications for linguistic relativity and psychological discounting}

In light of the discussion in sections 1.2 .1 and 1.2 .2 the widespread "weak-" versus strong-FTR typology would seem to ignore both the extent to which future tenses tend to encode modal notions, and potentially correlated cross-linguistic differences in the grammaticization of modality. Such differences give rise to radically different hypotheses about the direction or proposed effects of FTR grammaticization. 
For instance, the largest typological difference between English on the one hand, and Dutch and German on the other, would seem to be that when making predictions, English speakers must use some modal verb (including will), whereas Dutch and German speakers are free to use the present tense or some modal verb. As such, we suggest that it is plausible that differences in discounting between English and Dutch or German speakers might be driven by increased attention to uncertainty among English speakers, potentially leading English speakers to discount more. On the other hand, it is plausible that this typological difference might give rise to differences in the extent to which the "future tenses" encode probability, from which we could derive the opposite hypothesis. For instance, Broekhuis and Verkuyl (2014) argue that zullen in (13) represents an epistemic weakening compared to present tense declarative sentences, e.g. Dat huis op de hoek stort in, "That house on the corner is collapsing" (see also Giannakidou \& Mari, 2018). Similarly, it is suggested that will encodes a weaker epistemic stance towards the denoted event than a present tense declarative sentence, e.g. (10) is more certain than (9) (Enç, 1996). However, this is complicated by the fact that constructions like (10) are not possible in the English FTR predictions, because English speakers must generally use will or another modal verb, and among those possible, will encodes the highest certainty. High frequency use of will might then result in English speakers being more future-orientated than Dutch speakers, because English grammatically requires speakers to mark FTR predictions with a high-certainty future gram, whereas Dutch speakers, when they mark the future, use a lower-certainty future one. If this line of argumentation is correct, the impacts of future tense use on discounting would be contingent on the relative frequency of the future tense compared with other modal expressions in a given language. However, such relative frequencies do not appear to be known.

Nonetheless, it seems like a more plausible conjecture that increased grammaticization of modality in English would simply lead to increased probabilistic discounting, but given the variety of options these languages have for expressing epistemic modality, it may be the case that such an effect is offset in Dutch and German by use of modal adverbs, adjectives, nouns, modal particles and mental state predicates. Clearly Whorfian research investigating the affects of grammaticization on psychological discounting needs to proceed with a better understanding of the relevant prospective typological differences. However, the extent to which modality is grammaticized, as well as the exact modal constituents of various future tenses, are, to our knowledge, not precisely known. Given the importance of such knowledge to further 
investigation of the impact of FTR grammaticization on psychological discounting, we present a detailed usage study exploring this question in English, Dutch, and German.

\subsection{Study overview and hypotheses}

To elicit usage we expanded Dahl's (1985, 2000) FTR questionnaires, on which the typology underpinning much Whorfian research on FTR grammaticization psychological discounting has been based (K. Chen, 2013). In the questionnaires, participants are given a context and a target sentence. The main verbs of the target sentences are given in the infinitive, and participants are tasked with conjugating these, given the context. We retained this methodology, but modified the contexts to include information of the likelihood (certain, uncertain, neutral) of the referenced event actually occurring. We also expanded the contexts' range of temporal distances from the speaker's "now," to enable investigation of whether there were cross-linguistic differences in the extent to which increased temporal distance resulted in increased use of epistemic modal constructions. We organize the presentation of results around three hypotheses:

First, it has been suggested that it is possible to use the present tense for FTR predictions in Dutch and German, but not English (Dahl, 1985, 2000, K. Chen, 2013) which we shall refer to as the "weak versus strong FTR hypothesis". To test this, we examined whether English speakers use will, be going to, or shall, more than Dutch speakers use zullen or gaan, or German speakers use werden. Given the described tendency of will to become increasingly obligatory in the prediction FTR mode, we further hypothesized that any cross-linguistic differences in future and present tense use will be most pronounced for predictions. In other words, we hypothesized that there will be an interaction between FTR mode and language, such that predictions will elicit the highest use of the future tense in English speakers.

Second, on the basis of suggestions that English modal verbs may be generally more grammaticized than Dutch or German modals (Bybee et al., 1994, Nuyts, 2000), we suggest that English may more strongly grammaticize epistemic modality, because some epistemic modal verb is obligatory in English predictions. As such, we hypothesized that English speakers will tend to modally mark their predictions using uncertain constructions more frequently than do Dutch and German speakers. We refer to this as the English uncertainty salience hypothesis.

Finally, given the above, we predicted that English speakers may also be more likely to use uncertain language as a function of temporal distance. In other words, there will be a two-way interaction between 
language and temporal distance such that slopes of uncertain language use over temporal distance will be positive in English but flat in Dutch and German. We refer to this as the English temporal modality hypothesis.

\section{Methods}

\subsection{Participants}

We had $N=907$ participants complete the modified questionnaire: $n=162$ (96 females) in English; $n$ $=581$ (382 females) in Dutch; and $n=164$ (93 females) in German. Data collection was between April 2015 and October 2019. The sample is not balanced across languages due to the incidental nature of the data gathering efforts, which were part of a broader research program investigating the Whorfian effects of the grammaticization of tense and modality on temporal and probabilistic discounting. English participants were recruited from the University of Oxford student body and from Prolific Academic. Dutch speakers were recruited from the participant research panel of the Max Planck Institute (MPI) for Psycholinguistics, Nijmegen, from Radboud University's research panel, Prolific Academic, and using a Qualtrics panel. German participants were recruited from the MPI participant research panel, and using a Qualtrics panel. Ethical approval for the study was granted by the University of Oxford internal review board, ref. no. R39324/RE001, and by the MPI ethical review committee. All participants were remunerated at approximately $€ 10$ per hour.

\subsection{Apparatus and materials}

The main apparatus of the study was the modified FTR questionnaire, which was presented to participants in their native language. To ensure translational equivalency, questionnaire sentences were first translated from (British) English into Dutch and German, and then back-translated and adjusted. The questionnaire was uploaded to the Qualtrics survey hosting platform using an automated python script, and was hosted on qualtrics.com. All participants completed the survey online. 


\section{$2.3 \quad$ Procedure}

Participants were asked to confirm their first language, then answered some demographic questions (age, sex, income, education, marital status, and employment status), which were recorded as control variables. Following this, three examples of the elicitation task were given with example responses. These were given in the past tense in order to avoid biasing participants through use of a particular FTR construction in the training materials. Finally, all participants completed all questions of the modified questionnaire, with questions presented in randomized order. Participants were advised that there "were no correct answers," and that they should complete the questionnaire sentences, "as though they were speaking to a close friend."

The study used a mixed design with language (English, Dutch, German) as a between-subject factor. There were 3 within-subject factors: (1) distance from present, i.e. temporal distance from speaker's "now" (from "day of" through nine gradations to $25+$ years in the future, as well as some indeterminate and/or ongoing questions, e.g. "If you eat that mushroom you DIE"); (2) probability condition (i.e. whether the context indicated the speakers was supposed to be certain, uncertain, or neutral); and (3) FTR mode (i.e. whether the context involved a prediction, an intention, or a schedule). Probability condition, and temporal distance were approximately balanced across the neutral and uncertain conditions, but the small number of certain questions precluded balance across this condition. Following (Dahl, 2000), and because we suspect cross-linguistic differences to be largest in this FTR mode, most contexts were predictive. This means that conditions are not fully balanced; see Supplementary Materials (SM) for details. Here are a few examples, one from each probability condition:

neutral

Context: It's no use trying to swim in the lake tomorrow...

Target: ...The water $\{\mathrm{BE}\}$ cold (then).

Context: Q: What is the weather forecast for next week?

uncertain

Target: A: It $\{$ RAIN $\}$ (a $50 \%$ chance).

Context: Don't bother investing in the tech industry...

certain

Target: ...Silicon Valley $\{$ CRASH $\}$ by 2018 (I'm very sure). 
All are in the prediction mode, but exemplify a variety of temporal distances. Where possible, common words for certainty and uncertainty (e.g. "possibly", "definitely") were avoided to minimize semantic priming.

\subsubsection{Classification of responses}

Because of the large number of text examples, $N=32,824$, it was necessary to automate the scoring of responses in terms of whether they used the present tense, future tense, or some kind of epistemic modal expression. We therefore wrote a key-word-based classification program in Python (Python Software Foundation, 2017), which we call the FTR-classifier. It is freely available for academic use ${ }^{7}$ The FTRclassifier categorizes responses according to which tense and/or modality words they contain. Since epistemic modality involves expressing degrees of possibility vs. certainty, it was appropriate to classify responses into six categories, which comprise the dependent variables in this study. In addition to the listed categories, we also reserve a category for responses using "bouletic" modal language, i.e. want, hope and other modal verbs relating to desires (Palmer, 2001), as well as the past tense (participants sometimes misunderstood and used the past tense). In practice, responses of these types are low frequency and are removed from the data and excluded below (see SM). Each are dichotomous, and coded with 1 to indicate a response is a positive example.

Our classification system presents some complications because, as in (14-18), modal modifiers, mental state predicates, and even modal verbs in Dutch and German can be used in combination with a "future tense" verb. This makes formal categorization rather useless from a cognitive-pragmatic perspective. For example, (14-15) are formally present tensed, while (16-18) are formally future tensed. However, all make reference to future time, and yet within tense categories, wildly different epistemic commitments are expressed. Since we are not interested in formal tense structure, and are rather attempting to explore differences in marking of the notional domains involved, it was appropriate to have epistemic modal morphemes "dominate" tense morphemes, such that responses like (16-18) would be classed as epistemic uncertainty (or certainty), and not also as future or present tense. We therefore class responses into the six categories below:

\footnotetext{
7 The FTR-classifier can be installed at: https://pypi.org/project/ftr-classifier/ source code is available at: https://github.com/ cbjrobertson/ftr_classifier and supplementary data and code including the analyses herein is available at: https://github.com/cbjrobertson/ typo-pub
} 
PRESENT TEnse: Responses were classed as present tense if they failed to be classed as any of the other categories and also conjugated the main verb in the present tense.

FUTURE TENSE: Responses were classed as future tense if they used commonly accepted "future" auxiliaries or explicit temporal adverbials. Any response exhibiting these words, without any additional modal epistemic words, was counted as future tense.

VERBAL UNCERTAINTY: expressions which used any of the modal verbs, including the Konjunktiv II müßte, but baring all other cognates of must, were categorized as verbal uncertainty. This includes modal verbs which may indicate probability rather than possibility. This may seem to lack granularity. However, since expressions of even moderate to high probability necessarily express some degree of uncertainty, it is arguably justifiable. In any case, key-word methodologies are unlikely to accurately classify natural language at fine enough resolution to separate responses expressing moderate probability from just possibility, especially in the more context-dependent word classes.

Verbal CERTAinty: Seemingly, the only high-certainty modal verb is must and cognates. Although Tables 2/4 indicate that these are not an important way of expressing epistemic certainty, we counted any response using them as verbal certainty.

LEXICAL UNCERTAINTY: All expressions using modal modifiers encoding probability or possibility were classed as lexical uncertainty. All expressions using mental state predicates apart from know/weten/wissen were classed in this category. Additionally, German and Dutch may allow for changes to a speakers epistemic commitment through the use of modal particles. However, because they mostly subtly "attenuate" the strength of other modal words (Nuyts, 2000), they generally operate at a finer epistemic resolution than does our coding scheme, and were ignored apart from wel/wohl (Dutch, German), which has been noted in the literature to express epistemic weakening (Gutzmann, 2009).

LEXICAL CERTAINTY: Any response using modal modifiers and/or modal particles encoding highcertainty were classed as lexical certainty. Our literature review indicated that, as far as we could tell, there are no examples of high-certainty mental state predicates. The highest might be know/weten/wissen, but I know it will rain tomorrow is closer to encoding evidentiality than pure epistemic modality, so it was appropriate to ignore know and its cognates (Nuyts, 2000).

Tables 2 4 present main key words used by the FTR classifier, along with frequency data and references to the literature. Tables 20 4 were compiled from (to the best of our knowledge) exhaustive lists of the 
epistemic modal and FTR grams in English, Dutch, and German, including low-frequency, dated, and peripheral words.

To check whether the FTR-classifier was accurate, expert human raters classified a subset, $N=555$ (186 English, 273 Dutch, 96 German), of the responses. When systematic differences were found, the FTR-classifier was adjusted to better replicate human judgement. After this process was complete, we calculated inter-rater reliability between the human and automated classifications using Krippendorff's alpha (Krippendorff, 1970; Krippendorff \& Hayes, 2007). All $\alpha$ s $>0.77$, and all but one are $>0.88$ or "almost perfect" agreement (Landis \& Koch, 1977) (see SM).

\section{Results}

We found there were significant between-group differences for a number of the demographic variables (see SM). While these demographics are unlikely to confound usage, as they are unlikely to affect both usage and first language spoken, we nonetheless include them as covariates below (Pearl \& Mackenzie 2018). Where inclusion of demographics caused model parameters to cross significance thresholds, we report it in the main text, otherwise assume inclusion did not result in substantive change.

In much of the hypothesis testing in the following analyses, multilevel modeling approaches are appropriate, as responses from a single participant are likely to be similar across different questions, and responses to a single question are likely to be similar across different participants. We follow research practice with these types of models by building models sequentially: we start with a model with no random components and only an intercept, then add random intercepts for participant and question, then any fixed effects of interest, then random slopes where appropriate, and finally demographic covariates Raudenbush \& Bryk, 2002, Twisk, 2006, Aguinis, Gottfredson, \& Culpepper, 2013, Legler \& Roback, 2019). At each step we use log-likelihood ratio tests to ascertain whether additional parameters improve goodness of fit compared with the previous model (Raudenbush \& Bryk, 2002, Twisk, 2006. Aguinis et al., 2013; Legler \& Roback, 2019). In all models, including random effects for question and participant dramatically improves model fit, indicating such approaches are appropriate. We can also conclude that there is significant consistency within and variation between participants with regards to their use of the various dependent variables we measure. 


\subsection{The weak versus strong FTR hypothesis}

The weak versus strong FTR hypothesis suggests that English speakers will be more likely to use the future tense and less likely to use the present tense than Dutch or German speakers. As initial exploratory evidence, we present Fig. 3, which plots usage by language and FTR mode; English speakers appear to use fewer present tense, and more future tense, constructions across all levels of FTR mode than do Dutch and German speakers (see SM for full descriptive statistics of dependent variables). To test whether this apparent difference was statistically significant, we estimated two series of multilevel logistic regression models, which regressed present tense and future tense over language, FTR mode, and their interaction, and allowed intercepts to vary by participant, and intercepts and slopes for language to vary by question. Results are reported in Table 5 , and Figs. 445 .

We find that Dutch and German participants tended to use significantly more present tense constructions than did English speakers, Table 5 Transforming model $\beta$ s to probabilities, we find that, compared with English, the predicted probability of using the present tense increases by $1073.42 \%$ (Dutch) and $542.71 \%$ (German). We also find that, compared with English, the predicted probability of using the future tense decreases by $71.17 \%$ (Dutch), and $61.73 \%$ (German). These results provide strong support for the weak versus strong FTR hypothesis.

We additionally find there are significant differences between Dutch and German speakers in terms of present and future tense use. Compared with Germans, Dutch speakers are more likely to use present tense constructions, $\beta=1.134, S E=0.259, z=4.374, p<0.001$, and less likely (trend level) to use future-tensed constructions, $\beta=-0.383, S E=0.233, z=-1.648, p=0.099$. This indicates that there are significant differences in terms of FTR grammaticization between two "weak-FTR" languages with formally similar tense systems.

We also included in the weak versus strong FTR hypothesis that there would be an interaction between FTR mode and language such that differences between English and Dutch or German would be largest for predictions. Despite non-significant log-likelihood ratio tests for including FTR mode as a predictor of present tense, Wald tests indicate there may be a significant negative effect of prediction. This indicates that English speakers used the present tense $66.15 \%$ less when making predictions compared with the grand mean. Significant positive interactions between Dutch and German and FTR mode as well as Figs. 45 indicate this differences is not present for Dutch and Germans. This support the weak versus strong 
FTR hypothesis; English speakers were less likely to use the present tense when making predictions, but Dutch and Germans were not.

We find no such differences for use of the future tense, Figs. 45, which does not support the weak versus strong FTR hypothesis. If English speakers use fewer present tense constructions but not more future tense constructions when making predictions, what are they using instead? To answer this question, we created a variable which was equal to 1 when future tense or any marker of uncertainty was used, and reran the analysis as for future tense. Results are reported in Table 5 and Fig. 6 .

There is now a significant positive effect of prediction, which indicates that English speakers tended to use the future tense or a word encoding uncertainty when making predictions significantly more the grand mean 8 Trend-level negative interactions between Dutch and German and prediction, as well as Fig. 6, demonstrate that this pattern does not hold for Dutch and German. These results indicate that the English grammaticization of prediction is not limited to use of will; rather it is distributed across a variety of future and modal construction types which tend to encode degrees of certainty.

\subsection{The English uncertainty salience hypothesis}

The English uncertainty salience hypothesis suggests that English speakers will be more likely to use uncertain language than Dutch or German speakers. Referring to Fig. 3, English speakers appear to use many more verbal uncertainty constructions (modal verbs) than do Dutch or German speakers, particularly for prediction, although some of this may be "made up for" in German through the use of lexical uncertainty constructions. We now focus on differences as a function of our probability manipulation (while continuing to include FTR mode as a covariate). To test for effects on uncertain language generally, we combined verbal uncertainty and lexical uncertainty into a single dichotomous variable which was positive when either was positive; we refer it as "uncertain". As before, we estimated a series of mixed logistic models which regressed uncertain marking over FTR mode, language, and probability condition, as well as the language by probability interaction, and allow intercepts and slopes for language to randomly vary by question and intercepts and slopes for probability condition to randomly vary by participant. Results are reported in Table 6 and Fig. 7

\footnotetext{
${ }^{8}$ Adding demographic controls causes this coefficient to cross significance thresholds, but only just, $\beta=0.768, S E=0.394, z=1.948, p$ $=0.051$.)
} 
In the neutral condition, Dutch speakers used 75.18\% less uncertain language, and and German speakers used $47.6 \%$ less uncertain language than English speakers. There is also a positive effect of the uncertain condition and a negative, though non-significant, effect of the certain condition, indicating that our probability manipulation was broadly successful at eliciting certain and uncertain modal language. Positive certain by Dutch and German interactions appear to be driven by significantly higher use of uncertain language in the English neutral condition, see Fig. 7

Additionally, there are negative and significant uncertain by Dutch and German interactions, driven by higher use of uncertain language in the English uncertain condition than in Dutch and German; Dutch speakers used $55.21 \%$ fewer, and German speakers used $45.79 \%$ fewer uncertain expressions than the model would predict if the English pattern were maintained.

These results lend strong support to the English uncertainty salience hypothesis: Dutch and German speakers used fewer uncertain expressions in the neutral and uncertain conditions than did English speakers. However, it should also be noted that pairwise comparisons reveal that Dutch speakers tended to use more uncertain language in the neutral condition than did Germans, $\beta=0.76, S E=0.24, z=$ 3.19, $p=0.001$.

A good way of visualizing these differences is through Principal Components Analysis (PCA), which is commonly used to reduce a number of related variables into an arbitrary and smaller set of linear components which parsimoniously account for shared variance between the original set of variables (Tabachnick \& Fidell, 2007). We conducted three PCA analyses, one for each language, on the means per FTR mode and participant for all the dependent variables except verbal certainty (see SM).

Inspecting Figs. 9 11 it is clear that the three languages appear to be quite different in terms of the relationship between usage and FTR mode. In English, schedules tend to be characterized by future and present tense use, while intentions and predictions are increasingly characterized by the encoding of modal notions of certainty. To a lesser extent, this pattern can also be discerned in German. However, Dutch predictions are almost equally characterized by variation along the axes of PC1 which seems to mostly represent future-present variation and $\mathrm{PC} 2$, which seems to mostly represent certain-uncertain variation. This is compatible with the suggestion that Dutch usage patterns are not nearly as sensitive to FTR mode as are English or German.

Taken together these results support the English uncertainty salience hypothesis. We find English 
speakers used relatively more uncertain terms than Dutch or German speakers, and the PCA indicates that English speakers appeared to be the most sensitive to FTR mode. However, Germans used more uncertain terms than Dutch speakers, and the PCA indicates that Germans seemed to be intermediate between Dutch and English speakers in terms of their sensitivity to FTR mode. This may indicate that cross-linguistic differences in the grammaticization of prediction may cut across the simple weak versus strong distinctions that have characterized research to date.

\subsection{The English temporal modality hypothesis}

The English temporal modality hypothesis suggests that English speakers are more likely to use uncertain language as a function of temporal distance than are Dutch and German speakers. As above, we estimated a series of mixed logistic regression models, which regressed uncertain language use over temporal distance, probability condition as well as the interaction between language and each of these. Intercepts were allowed to vary by participant and intercepts and slopes for language were allowed to vary by question. Table 7 and Fig. 12 present the results. There are significant effects of Dutch, German, and probability condition, but these mostly duplicate our earlier findings. We focus here on effects relating to temporal distance.

There is a near-significant positive effect of log-scaled temporal distance; this indicates that the odds of an English speaker in the neutral condition using an uncertain term increased by $15.38 \%$ for every doubling of temporal distance the present. Conversely, a significant negative Dutch by temporal distance interaction indicates that Dutch speakers are not more likely to use uncertain language as a function of temporal distance. On the other hand, a non-significant German by temporal distance interaction indicates that Germans are similar to English speakers. Indeed, the odds of German speakers using an uncertain term increased by $13.59 \%$ for each doubling of temporal distance. This effect is significant at the trend level, $\beta=0.127, S E=0.077, z=1.647, p=0.19^{9}$

These results give mixed support to the English temporal modality hypothesis. In the neutral condition, English speakers were more likely to use uncertain language as they referred to events farther into the future, but so were Germans. On the other hand, Dutch speakers were not more likely to use uncertain language as a function of temporal distance. In this analysis we again find support for the sug-

\footnotetext{
${ }^{9}$ See SM for discussion of the effects of temporal distance in the certain and uncertain conditions.
} 
gestion than German may be intermediate between Dutch and English in terms of the grammaticization of prediction 10

\section{Discussion}

\subsection{Summary of findings}

Taken together, these results generally support the hypotheses proposed, and where results diverge from predictions, they present illuminating insights. We first summarize key findings, then discuss various implications.

The weak versus strong hypothesis suggests that English speakers use a greater number of future tensed constructions than Dutch and German speakers, and that this effect will be strongest in the predictive FTR mode. It is broadly supported; as predicted, English speakers used more future tense constructions and fewer present tense constructions than did Dutch or German speakers. However, our subsidiary suggestion that FTR mode would interact with language was only supported for the present tense, not the future tense. This appeared to be because when making predictions English speakers were not using the future tense exclusively; rather, they tended to encode the relative certainty of the prediction using either will or another less certain modal verb, i.e. could, can, may, might of should. Additionally, we note that Dutch speakers were more likely than Germans to use the present tense, which indicates that there may be salient differences in FTR grammaticization between weak-FTR languages.

The English uncertainty salience hypothesis is also generally supported; English speakers used more uncertain language, in both the uncertain and neutral conditions, and we find this is primarily because English speakers used more uncertain modal verbs. However, we also note that Germans used more uncertain terminology than did Dutch speakers, largely because of their use of lexical uncertainty constructions, i.e. mental state predicates, modal modifiers, or modal particles. Additionally, in the PCA analysis, we note a cline from English to German to Dutch in the extent to which FTR mode seems to be differentially grammaticized, which suggest that German grammaticization of modality is intermediate between English and Dutch.

\footnotetext{
${ }^{10}$ Given we have suggested that the "future tenses" in these language may encode modal notions, we also regressed future and present tense use over temporal distance, as this might constitute use of uncertain language as a function of temporal distance, but we find no effects (see SM).
} 
The English temporal salience hypothesis is supported with regard to the difference between English and Dutch, but not English and German; we find that English and German, but not Dutch, speakers are more likely to use uncertain language as a function of temporal distance (in the neutral condition). In this sense, we can again place German between English and Dutch in terms of the grammaticization of prediction. Future and present tense usage was not sensitive to temporal distance (SM).

Taken together, these findings suggest that the grammaticization of FTR and modality may be related. While the language sample is small, we find that English use of future tense and modal terminology appears to be generally higher than Dutch or German, which may suggest these grammaticization processes tend to be correlated. However, we did not expect to find such marked differences between Dutch and German; German speakers used more future tense, and uncertain construction, and their usage was more sensitive than Dutch speakers to FTR mode and temporal distance; these findings suggest that detailed usage studies will be necessary to adequately understand the prospective typological differences which may be implicated in Whorfian effects.

\subsection{Tense should not be isolated from modality in investigations of the grammaticization of prediction}

In testing the weak versus strong hypothesis, we unexpectedly find that the interaction between language and FTR mode was not significant for the future tense and only became significant when we included the other modal verbs and uncertain expressions in the dependent variable. This suggests that linguistic analyses which look at single future grams in isolation may be misleading. While it is not untrue that will is sensitive to FTR mode, our findings suggest such sensitivity is part of a more general grammaticization of predictions. This finding supports the utility of cognitive-pragmatic approaches, which begin with a notional domain and ask what different types of constructions tend to express it, rather than starting with a particular gram and asking how its use is distributed across different contexts (Nuyts, 2000). Our results suggest that the encoding of epistemic certainty for FTR predictions is distributed across a wide set of word classes, and that will, shall, or be going to may be best construed not as strict "tenses" but rather as high-certainty options among a set of modal verbs which obligatorily encode degrees of epistemic commitment to a future prediction. This suggests that economists working on linguistic 
relativity and FTR should seek to characterize cross-linguistic differences in the grammaticization of (future) predictions, which our results suggest are a more appropriate typological basis for making hypotheses about psychological discounting than the tense-centered dichotomous approaches presently predominant K. Chen, 2013, S. Chen et al., 2017, Chi et al., 2018, Fasan et al. 2016, Figlio et al. 2016. Galor et al., 2016; Guin, 2017; Hübner \& Vannoorenberghe, 2015a Karapandza, 2016, Kim et al., 2017. Liang et al. 2018, ?, ?] Mavisakalyan \& Weber, 2018, Mavisakalyan et al., 2018, Pérez \& Tavits, 2017. Roberts et al. 2015 Sutter et al., 2015: Thoma \& Tytus, 2018).

\subsection{Implications for the dichotomous FTR typology}

Do our results corroborate or undermine the suggestion that typologies based on the grammaticization of prediction would positively correlate with the existing dichotomous typology (K. Chen, 2013)? It could be the case that the grammaticization prediction and the grammaticization of (future) time tend to be unrelated. Alternatively, it could be the case that both result from a unified underlying process, which would mean they would tend to be correlated. The fact that we note an apparent correlation in our small language sample, as well as the robust tendency for future tense grams to develop from modal language (Bybee \& Dahl, 1989, Bybee et al. 1994; Dahl, 2000), suggests that both epistemic modal grams and future tenses are late emerging in the processes of grammaticization (Nuyts, 2000, and the epistemic "unknowability" of future events, lead us to suggest that the latter is more likely to be the case.

However, taken together our results only partially support this conjecture. Compared with Dutch and German speakers, we find that English speakers used significantly more future tense constructions, and significantly fewer present tense constructions. We additionally find that English speakers used significantly more uncertain expressions than Dutch or German speakers, and that English speakers usage seemed the most sensitive to FTR mode, Fig. 9.11. These results suggest that the grammaticization of future time and future modality may tend to be related. On the other hand, we find that German speakers used more uncertain terminology and more future tense constructions than did Dutch speakers, and that both English and German speakers used more uncertain language as a function of temporal distance in the neutral condition, while Dutch speakers did not. Indeed, slopes for use of uncertain language as a function of temporal distance in English and German speakers were not significantly different. This indicates that the existing dichotomous typology may be too coarse to to accurately 
capture cross-linguistic differences in the grammaticization of prediction.

Suggested ordinal FTR grammaticization typologies are also undermined by our results. K. Chen (2013) proposes a cline in FTR grammaticization strength which goes from weak to strong: 1) languages with no future tense at all (Finnish, Chinese), 2) languages with non-obligatory future tenses (Dutch, German), 3) languages with obligatory but lexical future tenses (English), and 4) languages with obligatory bound inflectional future tenses (French, Spanish). However, our results indicate that there are substantive and significant differences in terms of the grammaticization of prediction between two languages which are formally very similar and both of type (2), i.e. Dutch and German. This leads us to conclude that extensive usage data will be needed in order to accurately identify cross-linguistic differences in the grammaticization of prediction, and that researchers should dispense with the notion that such differences can be captured using purely formal criteria, or by a single variable in large-scale statistical analyses. These suggestions echo work on manner of motion salience in path versus satellite framed languages wherein initial categorical typological approaches have been found to fail to adequately capture the domain salience of manner of motion between languages within typological category, and researchers have increasingly argued that usage-based clines of domain salience are more appropriate Antuñano, 2008, Slobin, 2006).

\subsection{Implications for proposed causal mechanisms}

What implications might these typological findings have for the causal mechanisms suggested to mediate a relationship between the grammaticization of FTR and psychological discounting, i.e. the causal models proposed in K. Chen (2013), and depicted in Figs. 1.2? Firstly, the present results indicate that the grammaticization of time and probability in FTR may tend to be entangled. In consideration of the fact that temporal and probabilistic discounting functions interact complexly in realistic models of psychological discounting (Vanderveldt et al. 2015), this suggests that causal models which focus exclusively on the relationship between grammaticization of future time and temporal discounting are likely to be misleading. Indeed, contemporary models of psychological discounting indicate that probability and time have a conditional relationship in terms of their impact on subject value. Vanderveldt et al. 2015 conducted a temporal discounting task under various probabilities. In such tasks, participants are asked to choose between a certain present reward and an uncertain larger-later reward, e.g. "would 
you prefer $£ 10$ now, or a $90 \%$ chance of receiving $£ 40$ in three months?". They find that a model of the following form best describes their empirical results:

$$
V=A /\left[(1+k D)^{s d} \times(1+h \theta)^{s p}\right]
$$

Where $V$ is the actual monetary value of a reward, $D$ and $\theta$ are temporal distance and odds against, respectively, $k$ and $h$ are parameters affecting the discounting rates, and $s d$ and $s p$ are scaling factors which have been found to best describe experimental evidence. This entails that psychological discounting is better described by a discounting plane, than a discounting curve, Fig. 13

How might cross-linguistic differences in the grammaticization of prediction interact with such complicated discounting processes? Firstly, it should be noted that the mechanisms proposed in K. Chen (2013) might still be in effect. However, such differences in beliefs about the temporal distance of and precision around future events would just as easily apply to probabilistic discounting, i.e. we might expect speakers of languages which more strictly grammaticize prediction to both have relatively more precise beliefs about, and relatively lower estimates of the probability of future events. We would thereby predict them to discount more steeply.

However, it should be noted that temporal discounting rates are affected by the probability associated with a reward much more so than the other way around. In other words, as the probability of a future reward decreases, temporal distance has an increasingly negligible affect on subjective value, but probabilistic discounting curves are relatively unaffected by temporal distance (Vanderveldt et al. 2015). We therefore suggest that differences in the grammaticization of probability (i.e. modality) may be the more important factor in driving observed cross-cultural differences in discounting-related behavior (K. Chen, 2013).

Our results also suggest it may not be trivial to disentangle time and probability in terms of the precise causal mechanisms which may mediate relationships between grammaticization, beliefs, and decisions. In testing the English temporal modality hypothesis we find that English and German, but not Dutch, speakers are more likely to use uncertain language as a function of temporal distance, which implies that time and probability are being confounded by these speakers. We might therefore suggest that speakers of such languages would tend to have higher $D$ parameters as a function of the extent to which they perceive distant events as increasingly uncertain. In other words, cross-linguistic differences might 
affect the beliefs about time and probability which form the input to typical discounting functions (Figs. 1.2), but also affect scaling parameters which define the strength of the conditional relationship between time and probability as a function of the extent to which a given language tends to use probabilistic language as temporal distance increases. Detailed psycholinguistic experimentation is clearly needed to disentangle this complexity.

\subsection{Limitations and future work}

Apart from the fact that the language sample is small and drawn from a single language family, one of the limitations of this study is that the results do not illuminate the extent to which the future grams in our languages encode modal notions. Inspecting Fig. 8, it seems reasonable to conclude that will encodes high-certainty; English speakers use will far less in the uncertain condition, and it is mostly replaced with the other English modal verbs which tend to encode relatively less certainty. This would lead us to suggest that the relative uncertainty encoded by will in example (9) compared with (10) does not project into the FTR space where will is the highest certainty modal verb generally grammatically permitted.

However, the question of whether zullen, gaan, and werden encode relatively more or less certainty than present tense FTR in Dutch and German remains largely unanswered. Inspecting Fig. 8 it seems as though present and future tense constructions are both replaced by uncertain language in the uncertain condition, indicating they are both encoding some form of high-certainty modality, but the relative differences in the encoding of modality between future and present tense remain difficult to infer from this data.

A finding of the present study which may be leveraged to investigate this question in the future is that random effects for participant were consistently a highly significant predictor of usage across all construction types. This indicates that individuals both tended to differ from each other, and exhibited some consistency in the types of constructions they employed in answering the FTR questionnaire. We note that this may be driven simply by response set bias in the questionnaire, i.e. some participants may have arrived over the course of completing questions at rote constructions which they gave in response to manipulations of probability, temporal distance, and FTR mode. Test-retest validation would need to be conducted to more clearly establish that observed patterns were driven by persistent "real world" 
usage habits rather than biases in the questionnaire. Nonetheless, we find that people tended to differ significantly in terms of the extent to which they used present, future, and modal constructions in our data. This is to be expected; in the languages in our sample, predictive commitment is spread across many word-classes, and even the most highly grammaticized of these classes - the modal verbs - are considered to be only semi-grammaticized (more so in English than Dutch or German) (Nuyts, 2000). Given the highly flexible nature of these constructions, we would expect usage patterns to be different between individuals, and also to reflect individual differences in belief about probability. Future research should attempt to correlate individual differences in the use of these construction types with delay and probabilistic discounting decisions, which would allow some insight into the extent to which future and present constructions encode modality for individuals.

An additional limitation of the present study is that it does not explore whether the cross-linguistic typological differences identified are associated with corollary differences in psychological discounting rates. This is an obvious next step.

\subsection{Conclusions}

While we find that the weak vs. strong-FTR typology does accurately predict differences between English (strong) and Dutch or German (weak), in terms of future and present tense usage, it mostly fails to adequately account for cross-linguistic differences in the encoding of modality. On the one hand, grammaticization of probability appeared to be partly correlated with the weak vs. strong typology; English speakers tended to encode notions of modality more than Dutch and German speakers, which appears to mostly be driven by a more highly grammaticized modal verb system. These results undermine the notion that FTR grammaticization is primarily about time, and call into question the validity of the causal mechanisms suggested in K. Chen (2013). If tense and modal FTR grammaticization are generally correlated, it may be the case that observed cross-cultural differences in discounting-related behavior are actually being driven by cross-linguistic differences in the grammaticization of probability, rather than

time. This suggests that economists who continue to research the effects of FTR grammaticization on temporal discounting can no longer ignore modality, or probabilistic discounting. On the other hand, we find that the grammaticization of prediction is not entirely explained by the weak vs. strongFTR typology. In many ways, including use of lexical uncertain constructions, and use of uncertain 
constructions as a function of temporal distance, German seemed to be between Dutch and English in terms of the extent to which probability was systematically encoded, a fact which could not have been predicted using formal criteria; usage data were necessary. Economists continuing to work on this question would do well to dispense with large-scale regression analyses which use the weak vs. strong-FTR typology as a predictor. Rather, detailed experimental work which combines behavioral economic techniques with usage-based typological linguistics should be employed to explore the precise relationships between cross-linguistic typological differences in the grammaticization of prediction, and individual differences in language usage and psychological discounting. 


\section{Tables}

Table 1: Example elicitation sentence

\section{CONTEXT:}

In December, talking about a third person's plans:

Target sentence (omit material within parentheses):

(In the summer), he $\{$ TRAVEL $\}$ to Morocco.

\section{Enter response below:}

In this example participants must conjugate the sentence "He TRAVEL to Morocco." A

typical answer in English might be "He will travel to Morocco" or "He is going to travel to

Morocco." 
Table 2: English classification of FTR tense and modality

\begin{tabular}{|c|c|c|c|c|c|}
\hline meta category & category & word or phrase ${ }^{1}$ & count $^{\mathrm{j}}$ & percent & justification \\
\hline \multirow{6}{*}{ verbal uncertain } & \multirow{6}{*}{ modal verbs } & might & 441 & $8.93 \%$ & indicates $\% 75$ probability ${ }^{\mathrm{a}}$ \\
\hline & & could & 317 & $6.42 \%$ & indicates possibility $^{\mathrm{b}}$ \\
\hline & & may & 270 & $5.47 \%$ & indicates $\% 50$ probability and/or permission ${ }^{\mathrm{a}}$ \\
\hline & & would & 83 & $1.68 \%$ & indicates possibility/conditional probability ${ }^{\mathrm{b}}$ \\
\hline & & should & 61 & $1.24 \%$ & indicates $\% 75$ probability ${ }^{\mathrm{a}}$ \\
\hline & & can & 42 & $0.85 \%$ & indicates possibility $^{\mathrm{b}}$ \\
\hline verbal certain & modal verbs & must & 3 & $0.06 \%$ & expresses necessity and/or obligation ${ }^{\text {a }}$ \\
\hline \multirow{9}{*}{ lexical uncertain } & \multirow{4}{*}{ mental state predicates } & expect & 42 & $0.85 \%$ & "to regard as probable"c \\
\hline & & think & 15 & $0.3 \%$ & encodes weakening of commitment ${ }^{\mathrm{d}}$ \\
\hline & & doubt & 3 & $0.06 \%$ & encodes weakening of commitment ${ }^{\mathrm{d}}$ \\
\hline & & reckon & & $0.04 \%$ & "to expect, plan, or intend to do something"c \\
\hline & \multirow{5}{*}{ modal modifiers } & probable & $\gamma$ & $3.89 \%$ & $\begin{array}{l}\text { "in a way that seems likely to prove true; with } \\
\text { likelihood"c }\end{array}$ \\
\hline & & likely & 104 & $2.11 \%$ & "having a high chance of occurring; probable"c \\
\hline & & possible & & $0.61 \%$ & $\begin{array}{l}\text { "qualifying a statement, and expressing contingency or } \\
\text { uncertainty"c }\end{array}$ \\
\hline & & potential & 18 & $0.36 \%$ & conveys uncertainty ${ }^{\mathrm{e}}$ \\
\hline & & maybe & 7 & $0.14 \%$ & "possibly, perhaps"c \\
\hline \multirow{4}{*}{ lexical certain } & \multirow{4}{*}{ modal modifiers } & definite & 73 & $1.48 \%$ & determinate, certain ${ }^{\mathrm{f}}$ \\
\hline & & sure & 34 & $0.69 \%$ & conveys certainty and/or sureness $^{\mathrm{e}}$ \\
\hline & & certain & 31 & $0.63 \%$ & determined, fixed $^{\mathrm{f}}$ \\
\hline & & for sure & 6 & $0.12 \%$ & as a certainty, without doubt ${ }^{f}$ \\
\hline \multirow{4}{*}{ future } & \multirow{4}{*}{ accepted future tenses } & will & 2941 & $59.55 \%$ & high frequency, central FTR auxiliary ${ }^{\mathrm{b}}$ \\
\hline & & be going to & 384 & $7.77 \%$ & indicates $\mathrm{FTR}^{\mathrm{g}}$ \\
\hline & & shall & 10 & $0.2 \%$ & expresses "only future time orientation"b \\
\hline & & about to & 2 & $0.04 \%$ & indicates near future \\
\hline present $^{\mathrm{k}}$ & present tense response & - & - & - & - \\
\hline \multicolumn{6}{|c|}{ 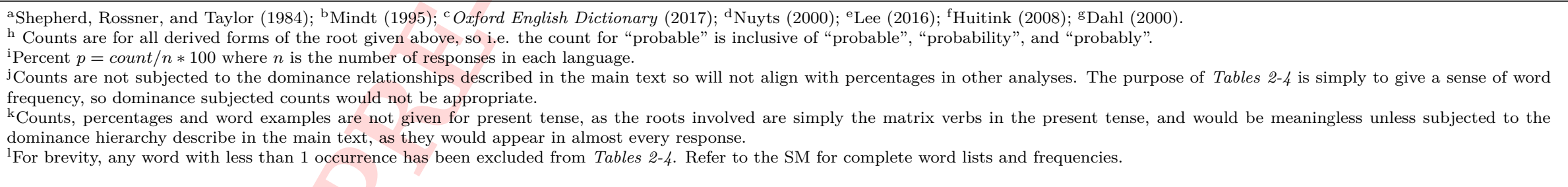 } \\
\hline
\end{tabular}


Table 3: Dutch classification of FTR tense and modality

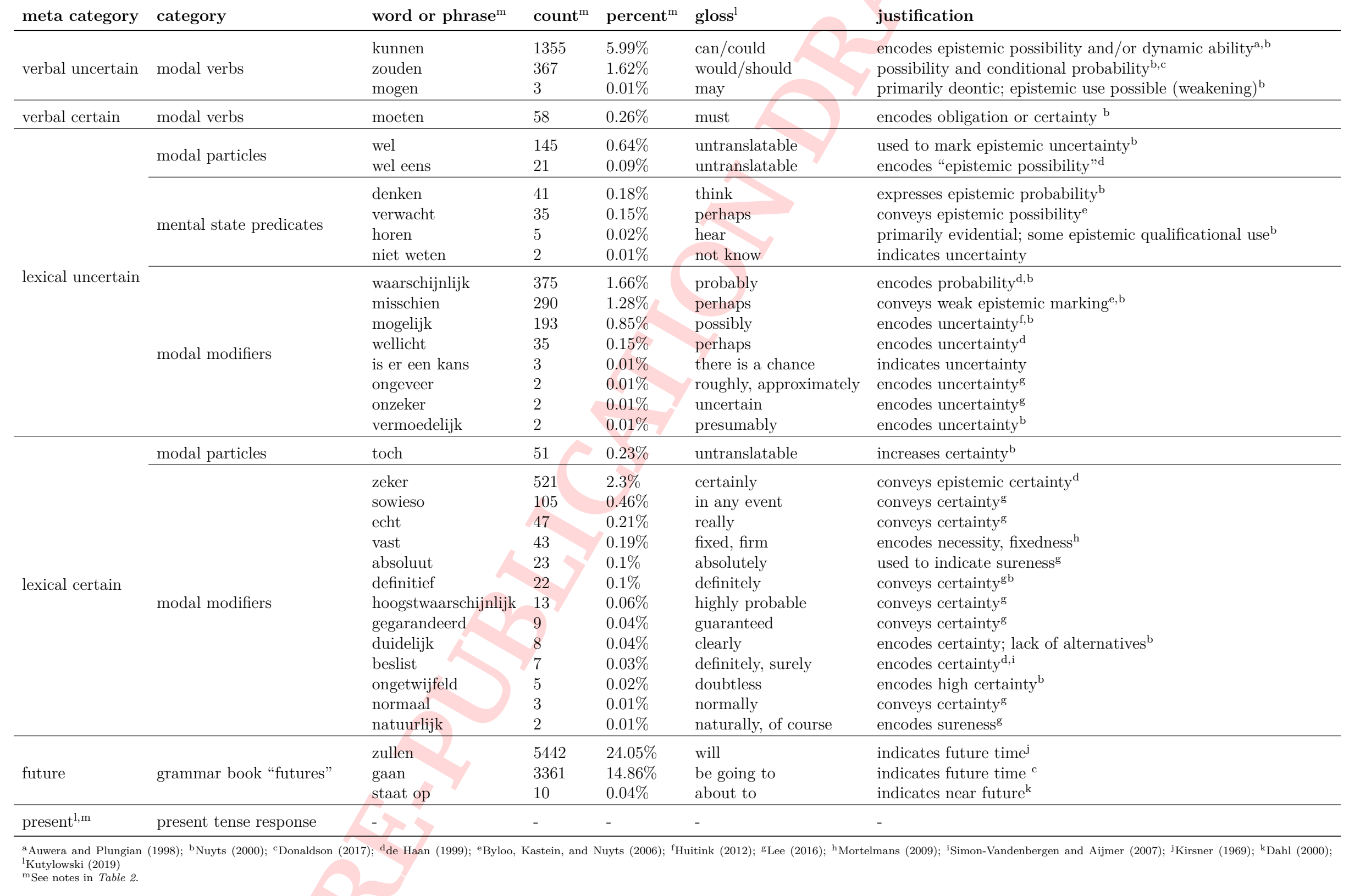


Table 4: German classification of FTR tense and modality

\begin{tabular}{|c|c|c|c|c|c|c|}
\hline meta category & category & word or phrase ${ }^{\mathrm{n}}$ & count $^{\mathrm{n}}$ & percent $^{\mathrm{n}}$ & gloss $^{\mathrm{k}}$ & justification \\
\hline \multirow{6}{*}{ verbal uncertain } & \multirow{6}{*}{ modal verbs } & können & 244 & $3.74 \%$ & may & \multirow{6}{*}{$\begin{array}{l}\text { conveys epistemic probability, weakened compared with } \\
\text { können }_{\text {PRES }}{ }^{\text {ab }} \\
\text { indicates uncertainty, i.e. } 50 / 50 \text { odds }^{c, e} \\
\text { used in our data to indicate uncertainty } \\
\text { some epistemic use possible; differences between indica- } \\
\text { tive and subjunctive forms unclear in literature }{ }^{\mathrm{a}, \mathrm{f}} \\
\text { epistemic indicator of probability }^{\mathrm{a}, \mathrm{b}} \\
\text { conveys epistemic possibility }^{\mathrm{a}}\end{array}$} \\
\hline & & können $_{\text {PRES }}$ & 179 & $2.74 \%$ & may & \\
\hline & & werden $_{\text {KONJ }}$ & 27 & $0.41 \%$ & would & \\
\hline & & sollen $_{\mathrm{KONJ}}$ & 24 & $0.37 \%$ & should & \\
\hline & & & 23 & $0.35 \%$ & should & \\
\hline & & mögen PRES & 17 & $0.26 \%$ & may & \\
\hline verbal certain & modal verb & müssen $_{\text {PRES }}$ & 7 & $0.11 \%$ & must & encodes certainty and/or necessity ${ }^{a, b, c, e}$ \\
\hline \multirow{14}{*}{ lexical uncertain } & modal particles & $\begin{array}{l}\text { vielleicht } \\
\text { wohl }\end{array}$ & $\begin{array}{l}143 \\
26\end{array}$ & $\begin{array}{l}2.19 \% \\
0.4 \%\end{array}$ & $\begin{array}{l}\text { maybe/presumably } \\
\text { presumably }\end{array}$ & $\begin{array}{l}\text { expresses weakened commitment }{ }^{g} \\
\text { weakens degree of commitment to proposition }\end{array}$ \\
\hline & \multirow{6}{*}{ mental state predicates } & erwarten & 115 & $1.76 \%$ & \multirow{6}{*}{$\begin{array}{l}\text { expect/believe } \\
\text { mean } \\
\text { believe } \\
\text { think } \\
\text { assume } \\
\text { reckon }\end{array}$} & encodes weakened commitment ${ }^{\mathrm{h}}$ \\
\hline & & meinen & 32 & $0.49 \%$ & & encodes probability ${ }^{\mathrm{a}}$ \\
\hline & & glauben & 18 & $0.28 \%$ & & encodes probability ${ }^{\mathrm{a}}$ \\
\hline & & denken & 12 & $0.18 \%$ & & encodes probability \\
\hline & & vermuten & 3 & $0.05 \%$ & & encodes uncertainty ${ }^{\mathrm{a}, \mathrm{h}}$ \\
\hline & & rechnen & 3 & $0.05 \%$ & & encodes probability ${ }^{\mathrm{a}}$ \\
\hline & \multirow{7}{*}{ modal modifiers } & wahrscheinlich & 424 & $6.49 \%$ & probably & conveys probability and/or likelihood ${ }^{\mathrm{a}, \mathrm{i}}$ \\
\hline & & möglicherweise & 183 & $2.8 \%$ & possibly & conveys possibility ${ }^{\mathrm{a}, \mathrm{i}}$ \\
\hline & & möglich & 114 & $1.75 \%$ & possible/possibly & uncertain epistemic qualification, i.e. $50 / 50^{\mathrm{a}}$ \\
\hline & & eventuell & 52 & $0.8 \%$ & potentially/perhaps & conveys probability ${ }^{\mathrm{i}, \mathrm{j}}$ \\
\hline & & unter umständen & 51 & $0.78 \%$ & in some circumstances & conveys likelihood and/or possibility ${ }^{\mathrm{a}, \mathrm{j}}$ \\
\hline & & vermutlich & 26 & $0.4 \%$ & presumably & encodes epistemic weakening $^{\mathrm{a}}$ \\
\hline & & womöglich & 19 & $0.29 \%$ & possibly/maybe & encodes probability and/or possibility ${ }^{\mathrm{i}}$ \\
\hline \multirow{6}{*}{ lexical certain } & \multirow{6}{*}{ modal modifiers } & sicher & 304 & $4.66 \%$ & surely/must & conveys certainty ${ }^{\mathrm{a}, \mathrm{b}}$ \\
\hline & & definitiv & 119 & $1.82 \%$ & definitely & conveys certainty \\
\hline & & bestimmen & 40 & $0.61 \%$ & certainly & indicates high certainty ${ }^{\mathrm{a}, \mathrm{m}}$ \\
\hline & & sicherlich & 36 & $0.55 \%$ & certainly & conveys certainty $\mathrm{d}, \mathrm{i}$ \\
\hline & & auf jeden fall & 11 & $0.17 \%$ & in any event & conveys certainty ${ }^{\mathrm{i}, 1}$ \\
\hline & & klar & 2 & $0.03 \%$ & clear, clearly & indicates clearness, certainty ${ }^{f}$ \\
\hline future $^{\mathrm{n}}$ & accepted future tenses & werden & 2559 & $39.19 \%$ & will/shall & future time auxiliary ${ }^{\mathrm{c}}$ \\
\hline present $^{\mathrm{n}}$ & present tense response & - & - & - & - & - \\
\hline
\end{tabular}


Modality and FTR in English, Dutch and German

Table 5: Parameters for models testing the weak versus strong hypothesis

fixed effects

random effects

\begin{tabular}{|c|c|c|c|c|c|c|c|c|c|c|c|c|c|c|}
\hline DV & IV & $\beta / \log O R$ & $\mathrm{SE}$ & $z$ & $p$ & group & component & variance & $\mathrm{SD}$ & slope:int $r$ & slope:slope $r$ & $\chi^{2}$ & $\mathrm{DF}$ & $p$ \\
\hline \multirow{9}{*}{ present tense } & (intercept) & -2.945 & 0.357 & -8.252 & $<0.001$ & \multirow{9}{*}{$\begin{array}{l}\text { participant } \\
\text { question }\end{array}$} & \multirow{9}{*}{$\begin{array}{l}\text { (intercept) } \\
\text { (intercept) } \\
\text { dutch slopes } \\
\text { german slopes }\end{array}$} & 2.065 & 1.437 & & \multirow{9}{*}{0.85} & 6721.64 & 1 & $<.001$ \\
\hline & dutch & 3.091 & 0.394 & 7.839 & $<0.001$ & & & 1.279 & 1.131 & & & 6635.64 & 1 & $<.001$ \\
\hline & german & 1.957 & 0.4 & 4.897 & $<0.001$ & & & 2.876 & 1.696 & -0.47 & & & & \\
\hline & intentions & -0.041 & 0.475 & -0.087 & 0.93 & & & 2.103 & 1.45 & -0.44 & & 466.75 & 5 & $<.001$ \\
\hline & predictions & -1.118 & 0.362 & -3.087 & 0.002 & & & & & & & & & \\
\hline & dutch*intentions & 0.065 & 0.481 & 0.135 & 0.892 & & & & & & & & & \\
\hline & german*intentions & -0.011 & 0.499 & -0.022 & 0.983 & & & & & & & & & \\
\hline & dutch*predictions & 0.95 & 0.384 & 2.477 & 0.013 & & & & & & & & & \\
\hline & german*predictions & 0.804 & 0.386 & 2.082 & 0.037 & & & & & & & & & \\
\hline \multirow{9}{*}{ future tense } & (intercept) & 1.261 & 0.567 & 2.225 & 0.026 & \multirow{9}{*}{$\begin{array}{l}\text { participant } \\
\text { question }\end{array}$} & \multirow{9}{*}{$\begin{array}{l}\text { (intercept) } \\
\text { (intercept) } \\
\text { dutch slopes } \\
\text { german slopes }\end{array}$} & 1.619 & 1.272 & & & 5253.31 & 1 & $<.001$ \\
\hline & dutch & -2.5 & 0.546 & -4.583 & $<0.001$ & & & 5.688 & 2.385 & & & 5836.24 & 1 & $<.001$ \\
\hline & german & -2.117 & 0.441 & -4.805 & $<0.001$ & & & 3.697 & 1.923 & -0.75 & & & & \\
\hline & intentions & 0.88 & 0.776 & 1.134 & 0.257 & & & 2.223 & 1.491 & -0.92 & 0.89 & 1043.13 & 5 & $<.001$ \\
\hline & predictions & -0.822 & 0.583 & -1.411 & 0.158 & & & & & & & & & \\
\hline & dutch*intentions & -0.882 & 0.773 & -1.142 & 0.254 & & & & & & & & & \\
\hline & german*intentions & -0.839 & 0.591 & -1.421 & 0.155 & & & & & & & & & \\
\hline & dutch*predictions & 0.933 & 0.569 & 1.64 & 0.101 & & & & & & & & & \\
\hline & german*predictions & 0.59 & 0.442 & 1.334 & 0.182 & & & & & & & & & \\
\hline \multirow{9}{*}{ future tense OR uncertain marking } & (intercept) & 2.602 & 0.385 & 6.751 & $<0.001$ & \multirow{9}{*}{$\begin{array}{l}\text { participant } \\
\text { question }\end{array}$} & \multirow{9}{*}{$\begin{array}{l}\text { (intercept) } \\
\text { (intercept) } \\
\text { dutch slopes } \\
\text { german slopes }\end{array}$} & 2.284 & 1.511 & & & 7172.89 & 1 & $<.001$ \\
\hline & dutch & -3.226 & 0.416 & -7.745 & $<0.001$ & & & 1.717 & 1.31 & & & 6355.77 & 1 & $<.001$ \\
\hline & german & -2.732 & 0.352 & -7.772 & $<0.001$ & & & 3.087 & 1.757 & -0.48 & & 610.24 & 5 & $<.001$ \\
\hline & intentions & -0.113 & 0.521 & -0.217 & 0.828 & & & 1.316 & 1.147 & -0.57 & 0.93 & & & \\
\hline & predictions & 0.833 & 0.391 & 2.129 & 0.033 & & & & & & & & & \\
\hline & dutch*intentions & 0.136 & 0.525 & 0.26 & 0.795 & & & & & & & & & \\
\hline & german*intentions & 0.054 & 0.422 & 0.128 & 0.898 & & & & & & & & & \\
\hline & dutch*predictions & -0.68 & 0.407 & -1.67 & 0.095 & & & & & & & & & \\
\hline & german*predictions & -0.632 & 0.326 & -1.935 & 0.053 & & & & & & & & & \\
\hline
\end{tabular}

Fixed effects $\beta$ coefficients represent the change in log-odds of each predictor compared to the intercept (in other words, changes in the log-scaled ratio of positive to negative examples). To convert these to probabilities in the body text, the $\beta$ 's are converted to odds by taking their exponent, i.e. odds $=\exp (\beta)$, and this is then converted to a probabilities as follows: $p=$ odds $/(1+$ odds $)$, so for instance if odds $=3 / 2$, then $p=1.5 / 2.5=.6$. Because the weak versus strong hypothesis involves comparing the two weak-FTR language

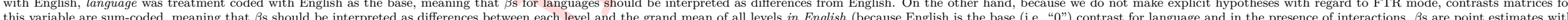
other predictors held to zero Hayes, 2013. Interactions between language and FTR mode then represent differences in usage as a function of FTR mode conditioned on language, 
Table 6: Parameters for the model testing the English uncertainty salience hypothesis

\begin{tabular}{|c|c|c|c|c|c|c|c|c|c|c|c|c|c|c|}
\hline & fixed effects & & & & & random effec & & & & & & & & \\
\hline DV & IV & $\beta / \log O R$ & $\mathrm{SE}$ & $z$ & $p$ & group & component & variance & $\mathrm{SD}$ & slope:int $r$ & slope:slope $r$ & $\chi^{2}$ & $\mathrm{DF}$ & $p$ \\
\hline \multirow{11}{*}{ uncertain language } & (intercept) & -3.275 & 0.297 & -11.033 & $<0.001$ & \multirow[t]{11}{*}{ participants } & (Intercept) & 1.8022 & 1.3425 & & \multirow{6}{*}{-0.02} & 2738.54 & 1 & $<.001$ \\
\hline & dutch & -1.422 & 0.207 & -6.877 & $<0.001$ & & certain slopes & 0.2509 & 0.5009 & -0.81 & & & & \\
\hline & german & -0.664 & 0.247 & -2.685 & 0.007 & & uncertain slopes & 4.0078 & 2.0019 & -0.42 & & 462.94 & 5 & $<.001$ \\
\hline & certain condition & -0.829 & 0.522 & -1.587 & 0.112 & & (Intercept) & 1.7721 & 1.3312 & & & 12886.21 & 1 & $<.001$ \\
\hline & uncertain condition & 5.199 & 0.466 & 11.165 & $<0.001$ & & dutch slopes & 0.2606 & 0.5105 & -0.21 & & & & \\
\hline & intention mode & 0.098 & 0.18 & 0.546 & 0.585 & & german slopes & 0.3922 & 0.6262 & -0.51 & & 183.61 & 5 & $<.001$ \\
\hline & prediction mode & 0.379 & 0.232 & 1.631 & 0.103 & & +1 & & & & & & & \\
\hline & dutch $*$ certain condition & 1.156 & 0.409 & 2.823 & 0.005 & & & & & & & & & \\
\hline & german $*$ certain condition & 1.488 & 0.436 & 3.414 & 0.001 & & & & & & & & & \\
\hline & dutch $*$ uncertain condition & -0.946 & 0.322 & -2.934 & 0.003 & & & & & & & & & \\
\hline & german $*$ uncertain condition & -1.367 & 0.366 & -3.732 & $<0.001$ & & & & & & & & & \\
\hline
\end{tabular}

As in Table 5 . Language is treatment coded with English as the base, and in this case, the probability condition is also treatment coded with neutral as the base, so effects of language should be interpreted as differences between Dutch or German and English in the neutral condition, and effect of FTR mode should again be interpreted as differences of FTR mode in the neutral condition. Effects of probability condition should be interpreted as differences between the certain or uncertain conditions and neutral, respectively, an 
Table 7: Parameters for the model testing the English temporal modality hypothesis

\begin{tabular}{|c|c|c|c|c|c|c|c|c|c|c|c|c|c|c|}
\hline & fixed effects & & & & & random effe & & & & & & & & \\
\hline DV & IV & $\beta / \log O R$ & $\mathrm{SE}$ & $z$ & $p$ & group & component & variance & $\mathrm{SD}$ & slope:int $r$ & slope:slope $r$ & $\chi^{2}$ & $\mathrm{DF}$ & $p$ \\
\hline \multirow{9}{*}{ uncertain language use } & (intercept) & -2.576 & 0.252 & -10.229 & $<0.001$ & \multirow{9}{*}{$\begin{array}{l}\text { participant } \\
\text { question }\end{array}$} & \multirow{9}{*}{$\begin{array}{l}\text { (intercept) } \\
\text { (intercept) } \\
\text { dutch slopes } \\
\text { german slopes }\end{array}$} & 1.6338 & 1.2782 & & \multirow{9}{*}{-0.08} & 1669.6 & 1 & $<.001$ \\
\hline & dutch & -1.421 & 0.175 & -8.105 & $<0.001$ & & & 2.5581 & 1.5994 & & & 9743.72 & 1 & $<.001$ \\
\hline & german & -0.531 & 0.218 & -2.435 & 0.015 & & & 0.2115 & 0.4598 & 0.08 & & \multirow{7}{*}{69.62} & \multirow{7}{*}{5} & \multirow{7}{*}{$<.001$} \\
\hline & temporal distance & 0.143 & 0.074 & 1.938 & 0.053 & & & 0.3914 & 0.6256 & -0.32 & & & & \\
\hline & probability & 3.359 & 0.406 & 8.28 & $<0.001$ & & & & & & & & & \\
\hline & dutch $*$ probability & -0.466 & 0.209 & -2.232 & 0.026 & & & & & & & & & \\
\hline & german $*$ probability & -1.164 & 0.224 & -5.193 & $<0.001$ & & & & & & & & & \\
\hline & dutch $*$ temporal distance & -0.085 & 0.045 & -1.871 & 0.061 & & & & & & & & & \\
\hline & german $*$ temporal distance & -0.016 & 0.055 & -0.281 & 0.778 & & & & & & & & & \\
\hline
\end{tabular}

Differing from Tables 5 and 6 . probability is treated as a continuous variable where certain $==-1$, neutral $==0$, and uncertain $==1$, which is justifiable as it is ordinal. As before, language is treatment contrast coded with English as the base. Ongoing and indeterminate levels of temporal distance are excluded, which leaves 9 levels specifying concrete time periods (today, tomorrow, one week, one month, six months, one year, two years, ten years, and twenty five+ years). These are converted to an interval variable by
taking the log of the number of days specified; $\beta$ s for Dutch and German therefore represent differences between Dutch or German and English, while $\beta$ f for temporal distance and probability should be interpreted as estimates when all predictors are held to 0 , i.e. in English, in the neutral condition, when temporal distance is at mean (approximately 86 days in the future) [Hayes, 2013). Interactions between Dutch, German, temporal distance, and probability should be interpreted as differences from this "base" condition, and the the following formula $p c=\left(e^{\log (O R)}-1\right) * 100$, where $\log (O R)$ is the $\beta$ of a given predictor, or the sum of several. 
Table 8: Example of the revised FTR-elicitation task conditions

\begin{tabular}{|c|c|c|c|}
\hline distance & probability & FTR-mode & question \\
\hline \multirow{9}{*}{ today } & \multirow{3}{*}{ neutral } & intention & $\begin{array}{l}\text { [Q: What you }\{\text { DO }\} \text { tonight?] A: I }\{\text { DINE OUT }\} \text { with } \\
\text { John. }\end{array}$ \\
\hline & & prediction & $\begin{array}{l}\text { [Q: What do you think about tonight's game?] A: Manch- } \\
\text { ester }\{\text { LOSE\}. }\end{array}$ \\
\hline & & scheduling & [Q: When $\{\mathrm{BE}\}$ the exam tonight?] A: It $\{\mathrm{BE}\}$ at $7 \mathrm{pm}$. \\
\hline & \multirow{3}{*}{ certain } & intention & $\begin{array}{l}\text { [Q: You want to see a film tonight? A: Sorry, I can't...] } \\
\text {...I \{DINE OUT\} with Ellie ( } 100 \% \text { decided }) .\end{array}$ \\
\hline & & prediction & $\begin{array}{l}\text { [Q: What do you think about the football this evening?] } \\
\text { A: Madrid }\{\text { LOSE } \text { ( } 100 \% \text { certain). }\end{array}$ \\
\hline & & scheduling & $\begin{array}{l}\text { [Q: When }\{\mathrm{BE}\} \text { the exam tonight? A: They have been the } \\
\text { same all week... } \ldots \text {. . it }\{\mathrm{BE}\} \text { at } 7 \mathrm{pm}(100 \% \text { certain }) \text {. }\end{array}$ \\
\hline & \multirow{3}{*}{ uncertain } & intention & $\begin{array}{l}\text { [Q: What you }\{\text { DO }\} \text { tonight? A: Hmmm... ] ...I }\{\text { DINE } \\
\text { OUT }\} \text { with Christine ( } 50 \% \text { decided }) .\end{array}$ \\
\hline & & prediction & $\begin{array}{l}\text { [Q: What do you think about the match tonight? A: It } \\
\{\text { BE }\} \text { hard to say... }] \text {...Arsenal }\{\text { LOSE }\} \text { ( } 50 \% \text { certain }) \text {. }\end{array}$ \\
\hline & & scheduling & $\begin{array}{l}\text { [Q: When }\{\mathrm{BE}\} \text { the exam tonight? A: I have to check the } \\
\text { class portal, but...] ...it }\{\mathrm{BE}\} \text { at } 7 \mathrm{pm}(50 \% \text { certain }) \text {. }\end{array}$ \\
\hline
\end{tabular}




\section{Figures}

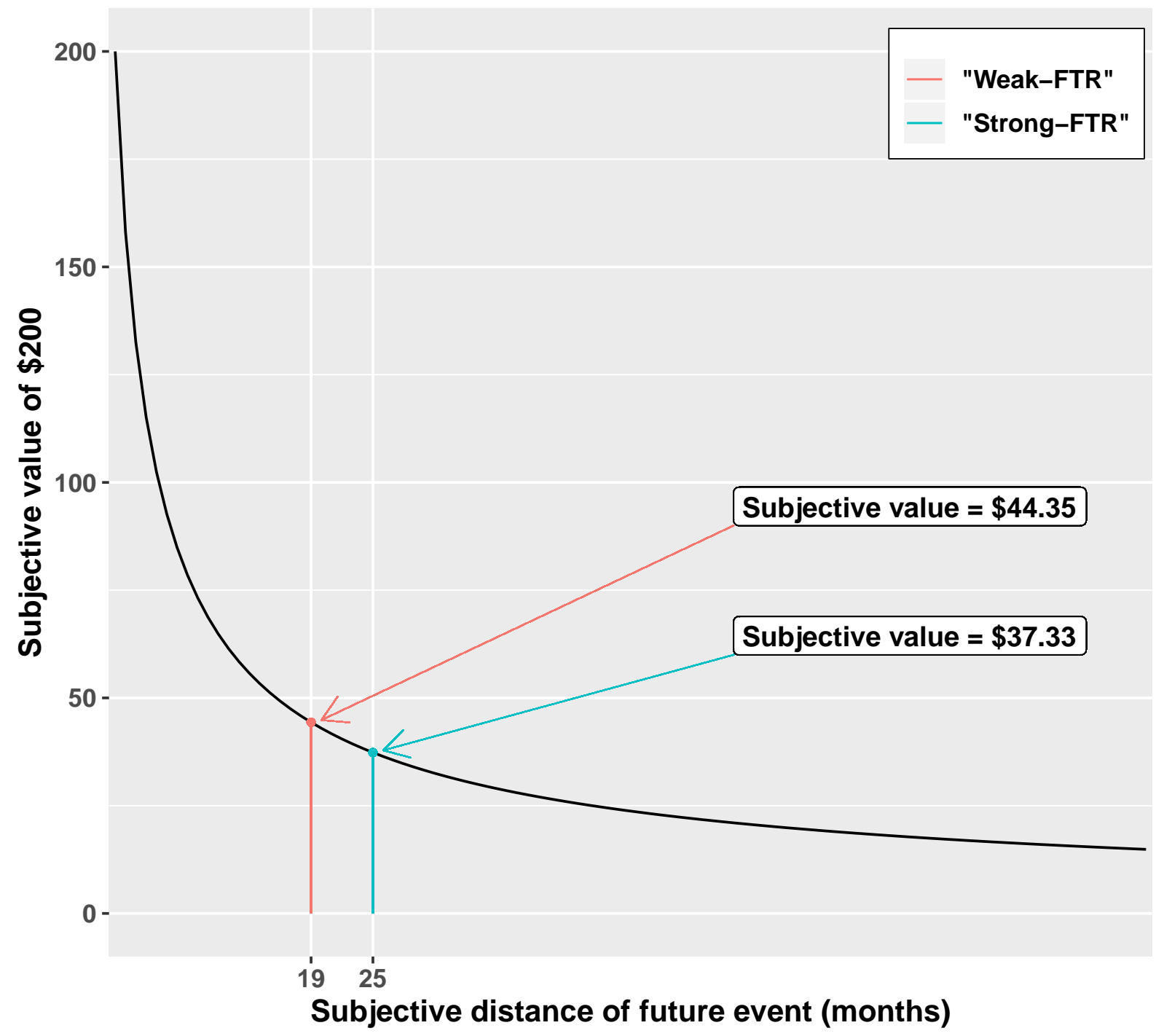

Figure 1: Simulated data demonstrating hypothesized effects of language on delay discounting. The discounting function plotted is the hyperboloid function $V=A /(1+k D)^{s}$, from Green and Myerson (2004) where $V$ is subjective value, $A$ is the objective amount ( $\$ 200$ in this case), $D$ is the delay, $b$ is a parameter that governs discounting rate, and $s$ is a non-linear scaling factor typically less than 1. This functions has been found to best describe empirical discounting rates in humans (Green \& Myerson, 2004, Green et al. 2014, Du et al. 2002, Vanderveldt et al. 2015). Plotted trainable parameters $s$ and $k$ are approximately average human discounting rates for the stated delay and value, i.e. $s=.7$ and $k=.4$ (from: Green \& Myerson 2004). Temporal distance: If speakers of weak-FTR languages perceive future events to be less temporally distant than speakers of strong-FTR languages, resultant valuation will be higher. 


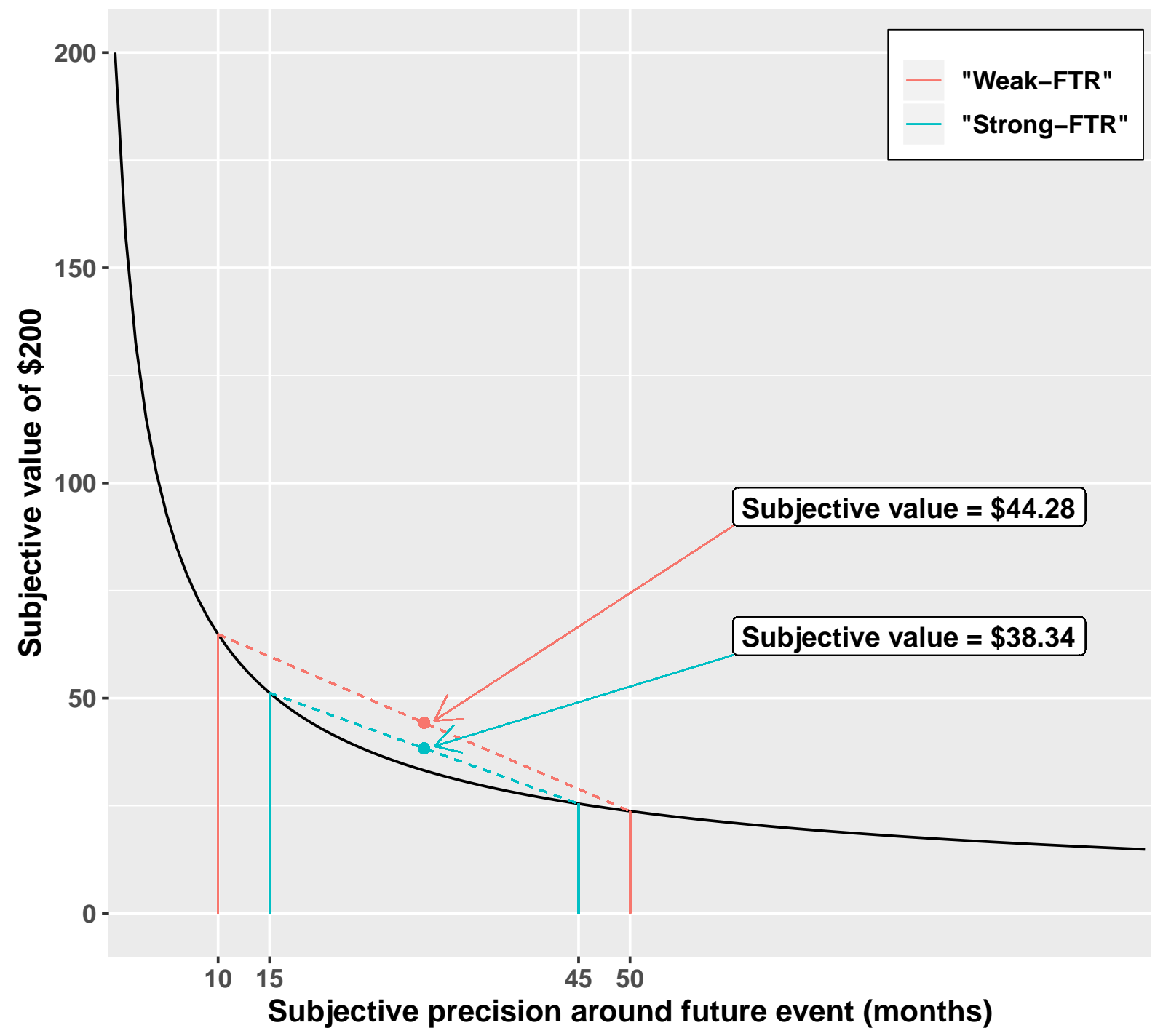

Figure 2: See Fig. 1 for notes on function and data source. Temporal precision: The easiest way to understand this hypothesized mechanism is to simplify the difference in perceived precision about future dates to two data points per speaker. Imagine two people are going to receive a reward on one of two dates. The probability of it falling on either date is uniform. To estimate the subjective value of the reward, each person must average the (discounted) value of the reward at both dates, i.e. for the weak-FTR speaker, who is not sure whether a reward will be received 10 or 50 months in the future (values are illustrative, not realistic) the subjective value is

$$
V=\frac{\sum_{i=1}^{n} 200 /\left(1+.4 D_{i}\right) \cdot 7}{n}=\$ 44.28
$$

While this is plotted with only 2 values per speaker, the principle holds for more complex, realistic probability distributions describing certainty around subjective distance of future events; providing the wider distribution is a mean preserving spread of the narrower one, and the discounting functions are strictly convex, the person with the wider distribution will have a higher estimation of future values and/or costs K. Chen 2013. 


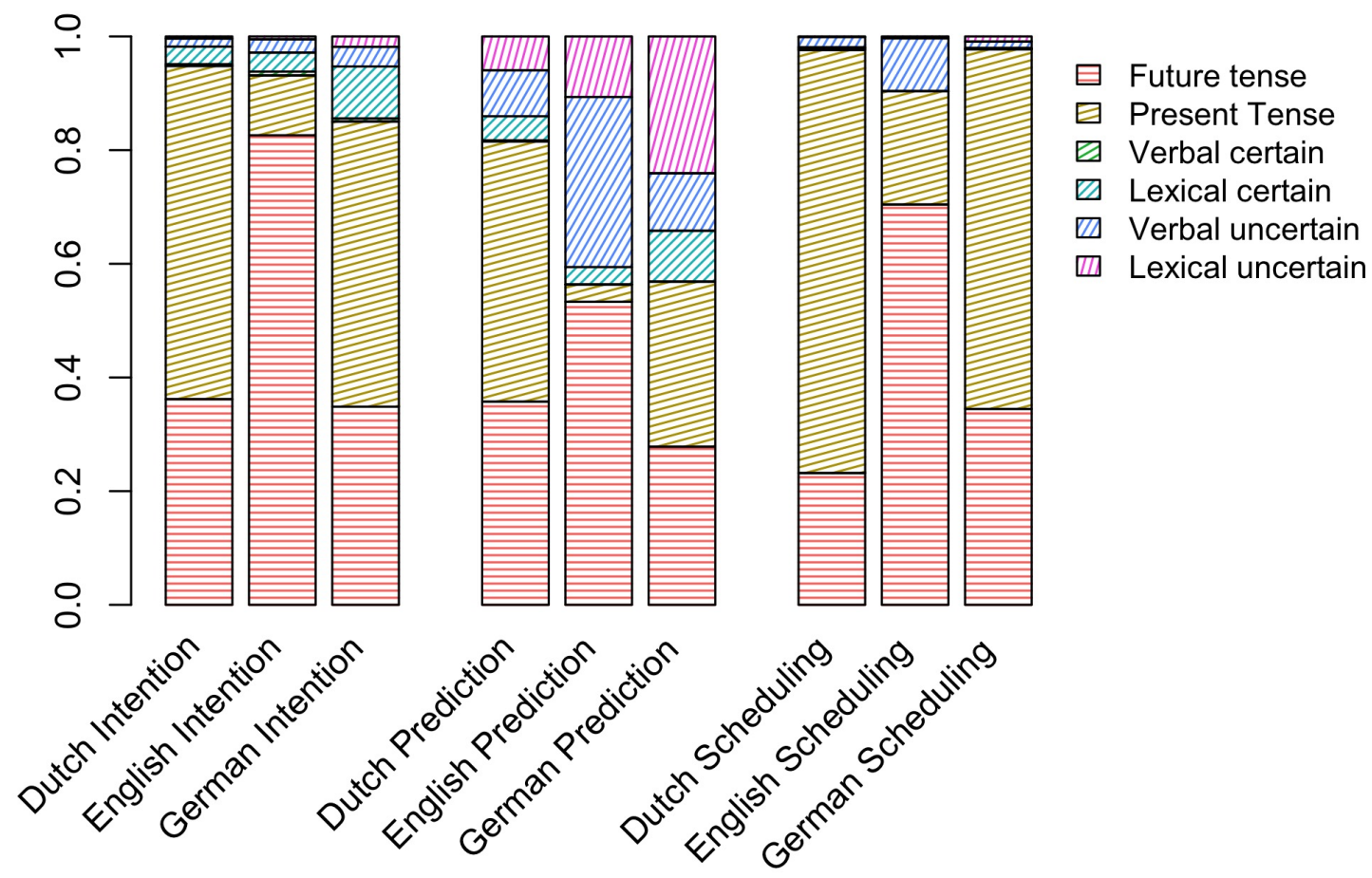

Figure 3: This and Fig. 8 present the mean usage of each of the dependent variables, normalized to sum to 1 , i.e. the proportions. While English uses significantly fewer present tense constructions and significantly more future tense constructions than Dutch and German, German speakers making predictions use almost as many uncertain constructions as do English speakers, mostly driven by higher frequency use of lexical uncertainty terms. Significant differences between Dutch and German in terms of the number of uncertainty terms are also present. Additionally, English speakers do use the present tense for FTR some of the time, especially in scheduling and intention FTR modes but also rarely when making predictions. 


\section{Predicted probability of using the present tense}

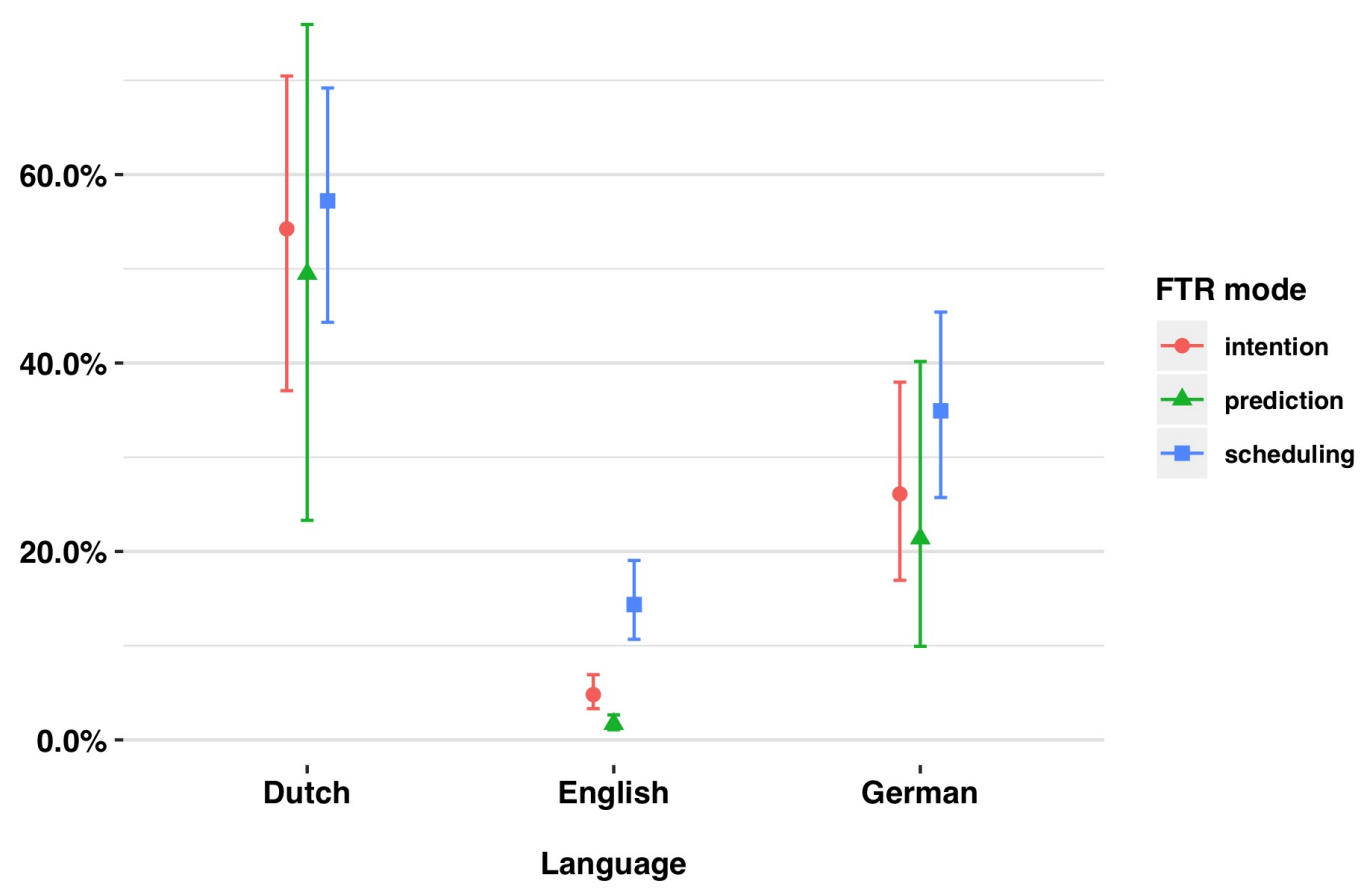

Figure 4: Percentages are the model's predicted probabilities for usage of present tense constructions by language and FTR mode. Confidence intervals are calculated using the $R$ package ggpredict (Lüdecke, 2019). In mixed-effects models calculating standard errors is complicated by the fact that mixed models contain multiple variance components. Above, as well as in Figs. 6, 7, and ??, CIs are calculated by matrix-multiplying a predictor $\mathrm{X}$ by the parameter vector $\mathrm{B}$ to get the predictions, then extracting the variance-covariance matrix $\mathrm{V}$ of the parameters and computing XVX' to get the variance-covariance matrix of the predictions. The square-root of the diagonal of this matrix represents the standard errors of the predictions, which are then multiplied by \pm 1.96 for the confidence intervals (Lüdecke 2019 . 


\section{Predicted probability of using the future tense}

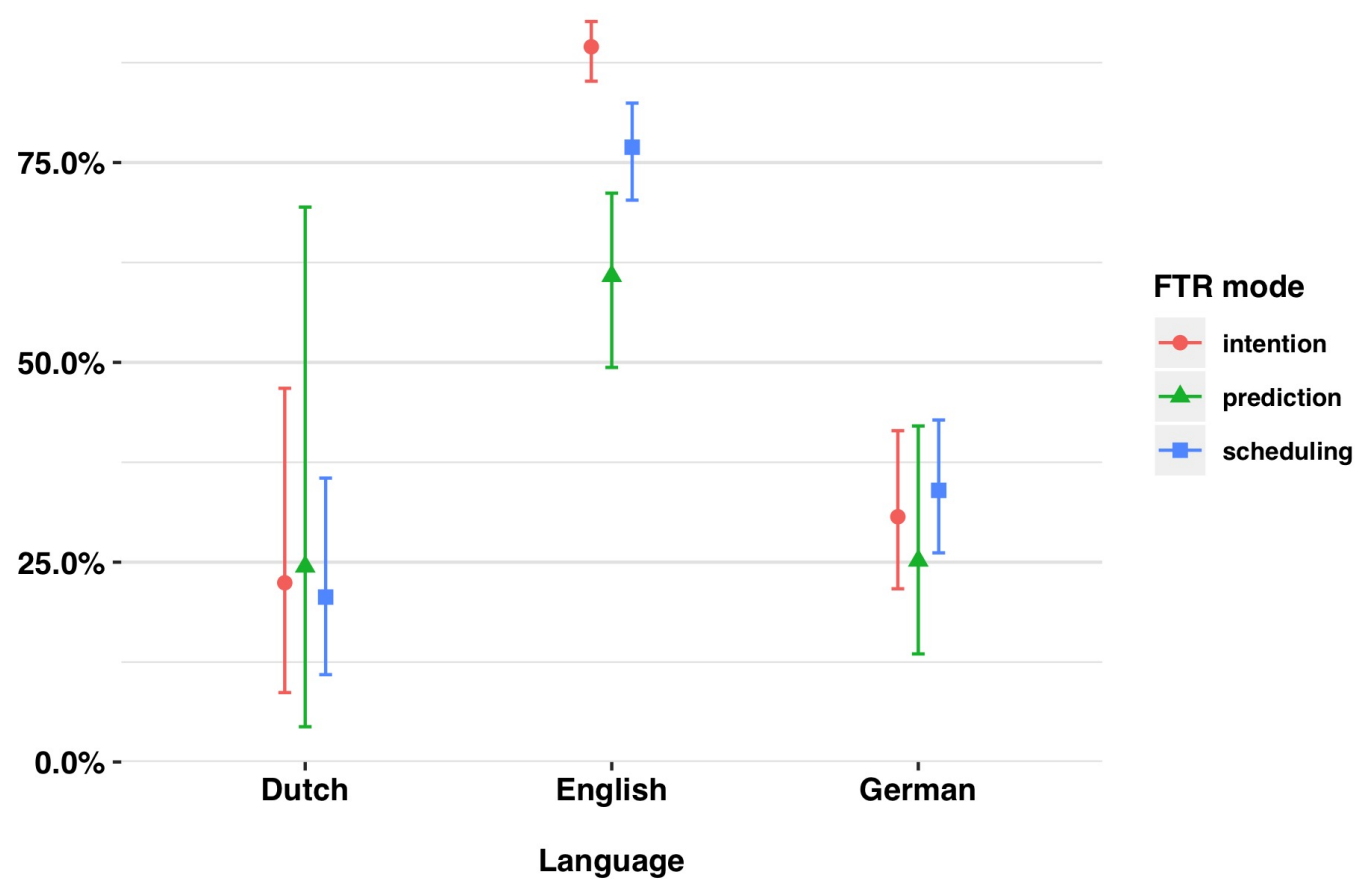

Figure 5: Percentages are the model's predicted probabilities for usage of future tense constructions by language and FTR mode. 
Predicted probability of using the future tense or an uncertain modal term $100.0 \%$ -

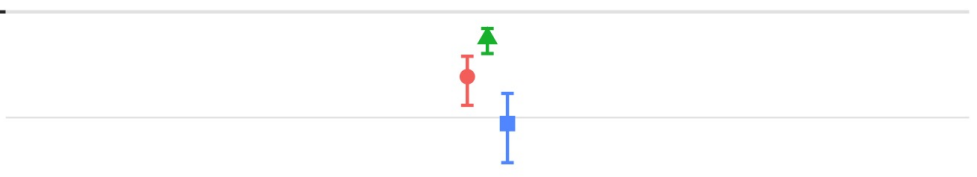

$75.0 \%$

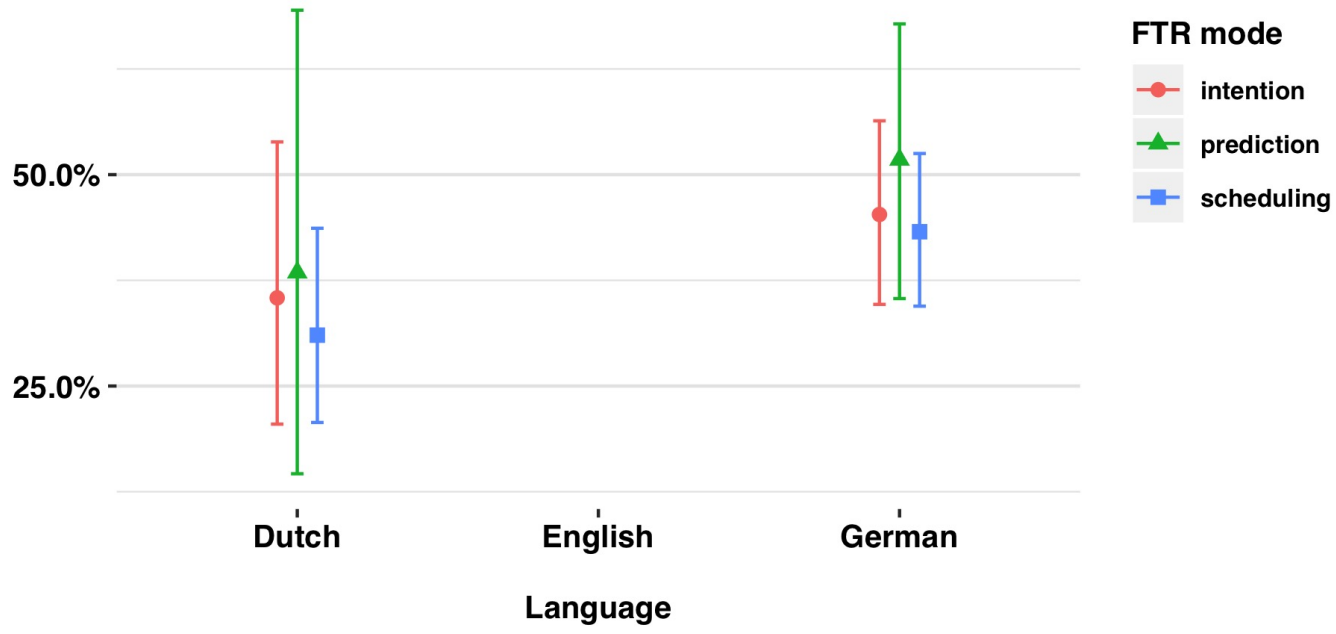

Figure 6: Percentages are the model's predicted probabilities for usage of future or any construction expressing uncertainty, by language and FTR mode. Compared with Fig. 5 the differences of the interaction between FTR mode and language are apparent. English speakers are much more likely to use the future tense or a markers of uncertainty when making predictions, and effect not apparent in Dutch or German. 


\section{Predicted probability of using uncertain language}

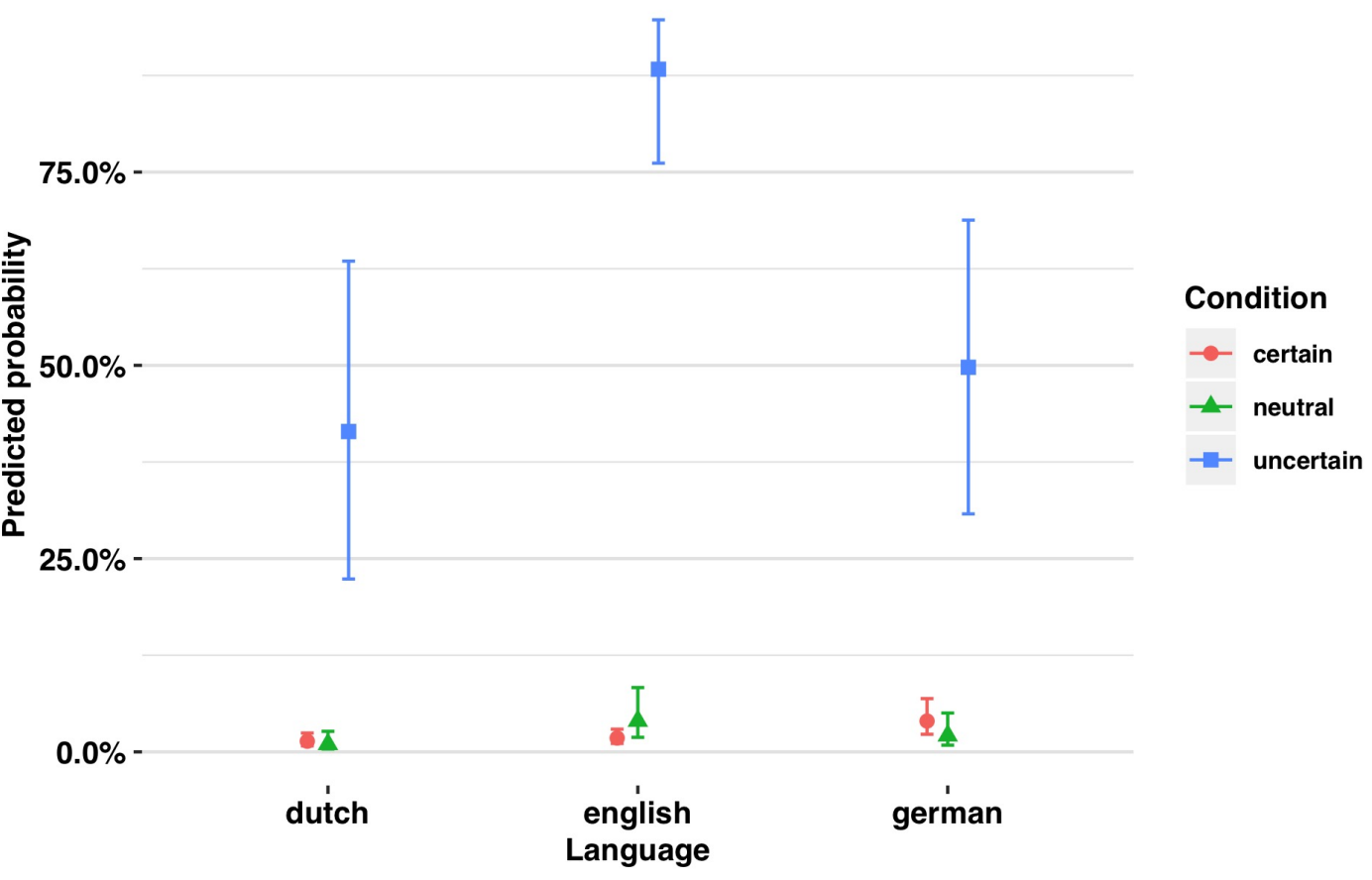

Figure 7: Percentages are the model's predicted probabilities for use of uncertain language (using a modal verb or other construction type) as a function of language and probability condition. In the neutral and uncertain conditions, Dutch and German speakers use less uncertain language than English speakers. 


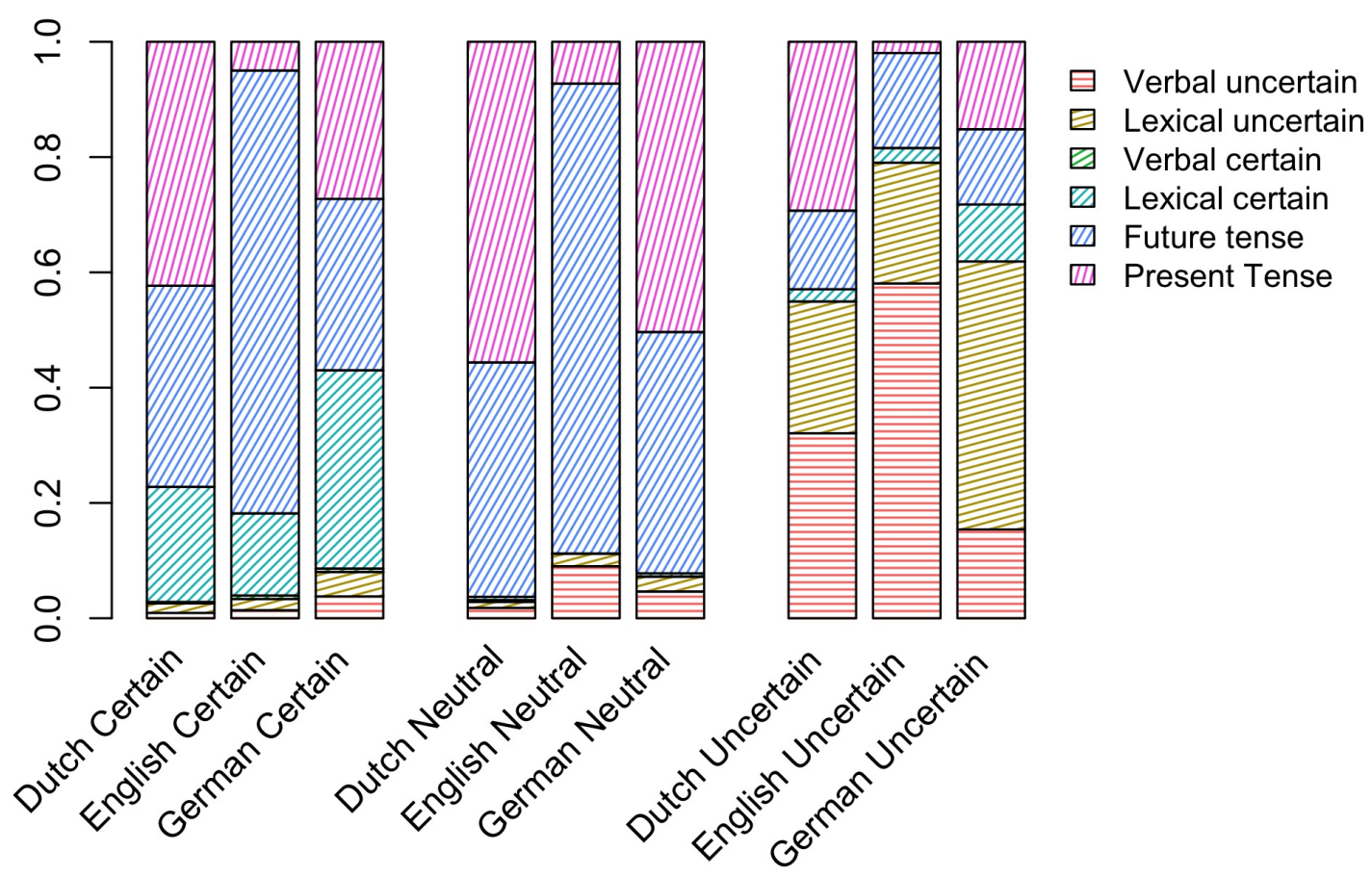

Figure 8: Proportion of use of different FTR expression types as a function of probability condition and language. In the uncertain condition, Germans appear to use more lexical uncertainty expressions than either English or Dutch speakers, but still used fewer uncertainty marked expressions than English speakers, largely because of frequent usage of modal verbs in English. 


\section{Original variable vectors and data over PC1 and PC1 in English}

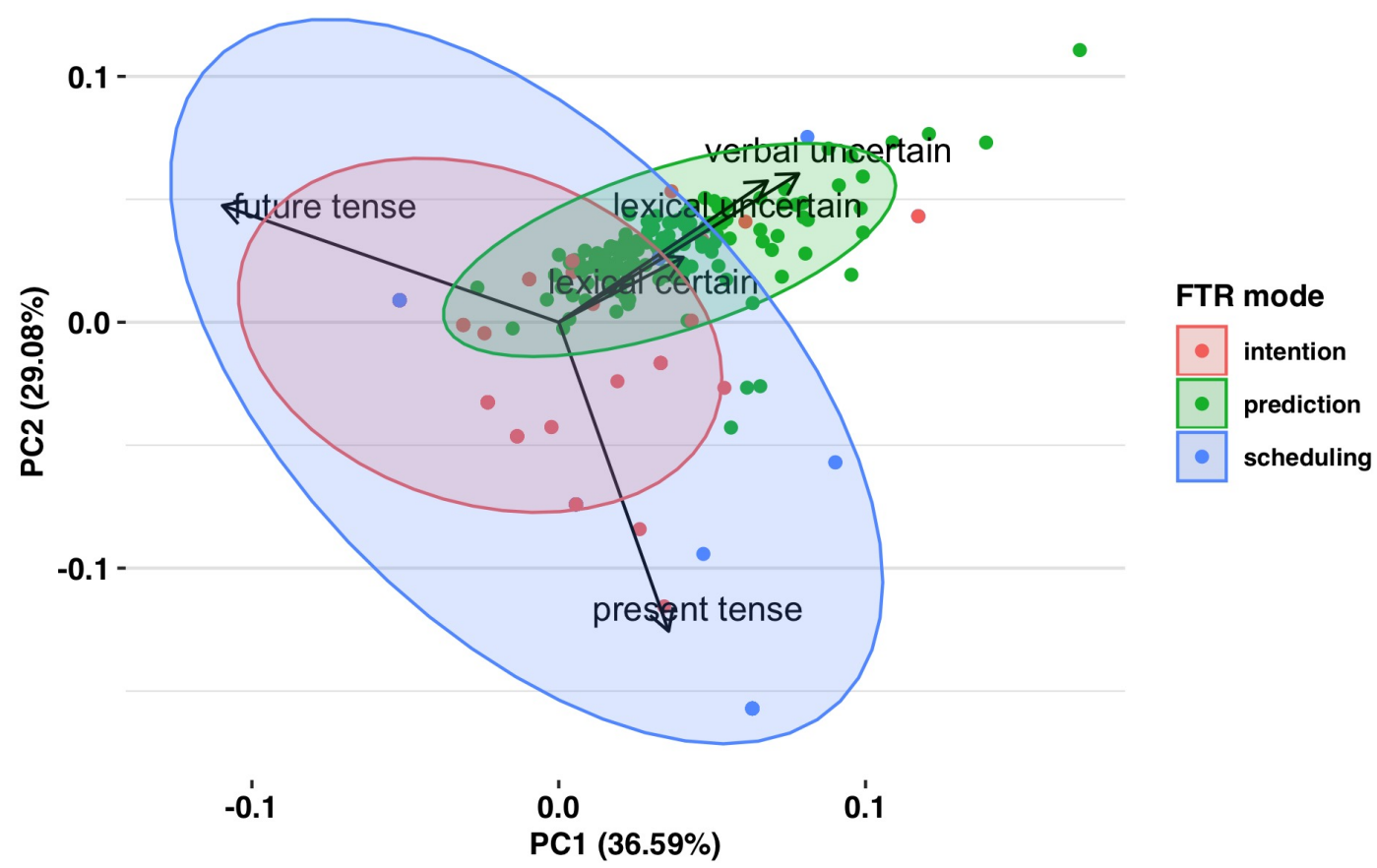

Figure 9: Plot of the English PCA results. In Figs. 911 the x-axes represent the first extracted component (PC1), while the y-axes represent the second (PC2). Scatter points represent raw data, and are colored by FTR mode, while ellipsoids are projections of the normal distribution over the data. Axis labels present the percentage of variance each component explains in the original data. Factor loadings are represented above by the angle measure (i.e. degree of alignment), and magnitude (arrow length) of the dependent variable vectors. For example, the vector for Dutch present tense is aligned almost perfectly with PC1 and the magnitude appears quite high; this indicates that present tense loads strongly on PC1. 


\section{Original variable vectors and data over PC1 and PC1 in Dutch}

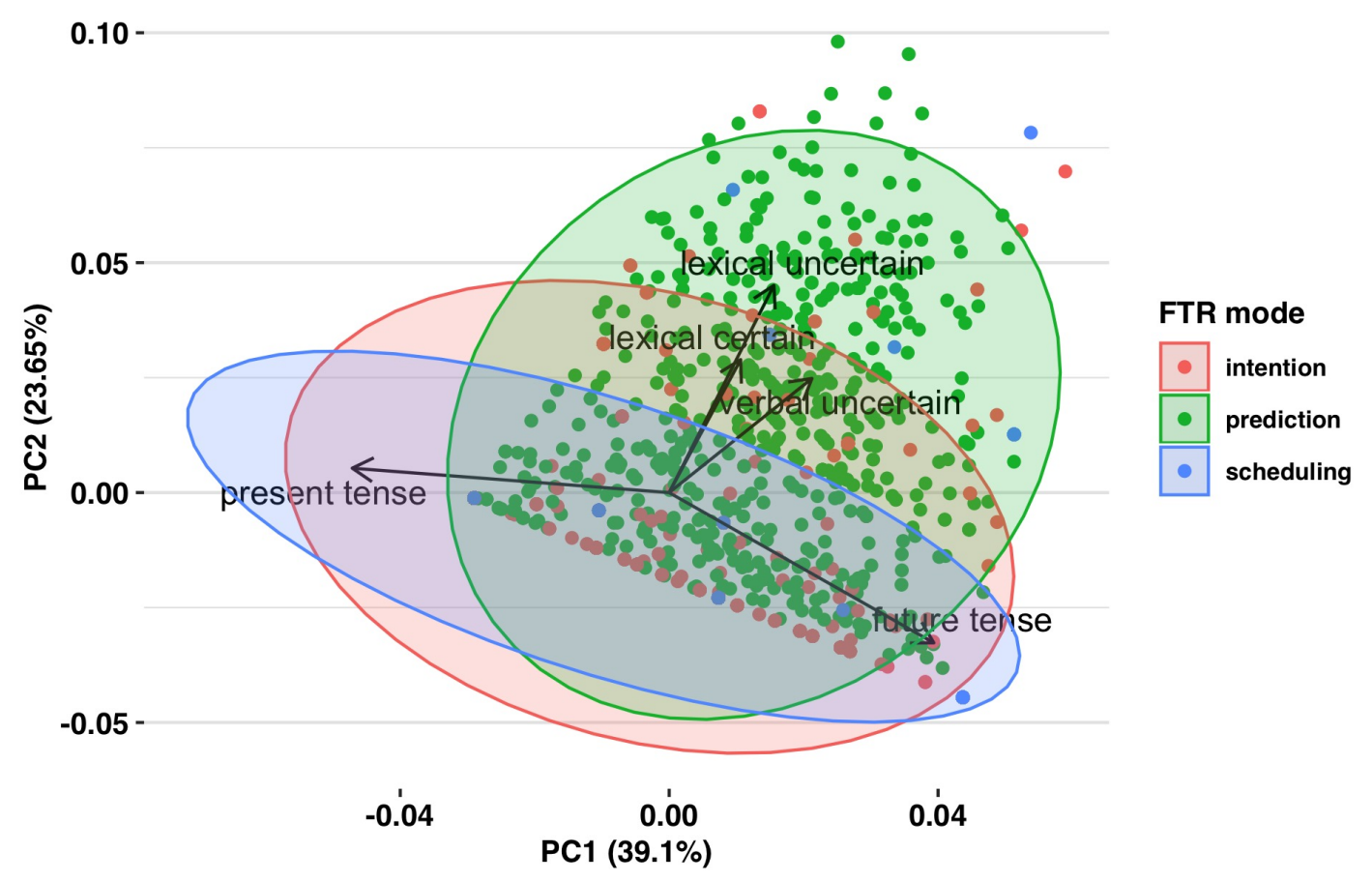

Figure 10: Plot of the Dutch PCA results; see Figs. 9 f for notes on interpretation. 


\section{Original variable vectors and data over PC1 and PC1 in German}

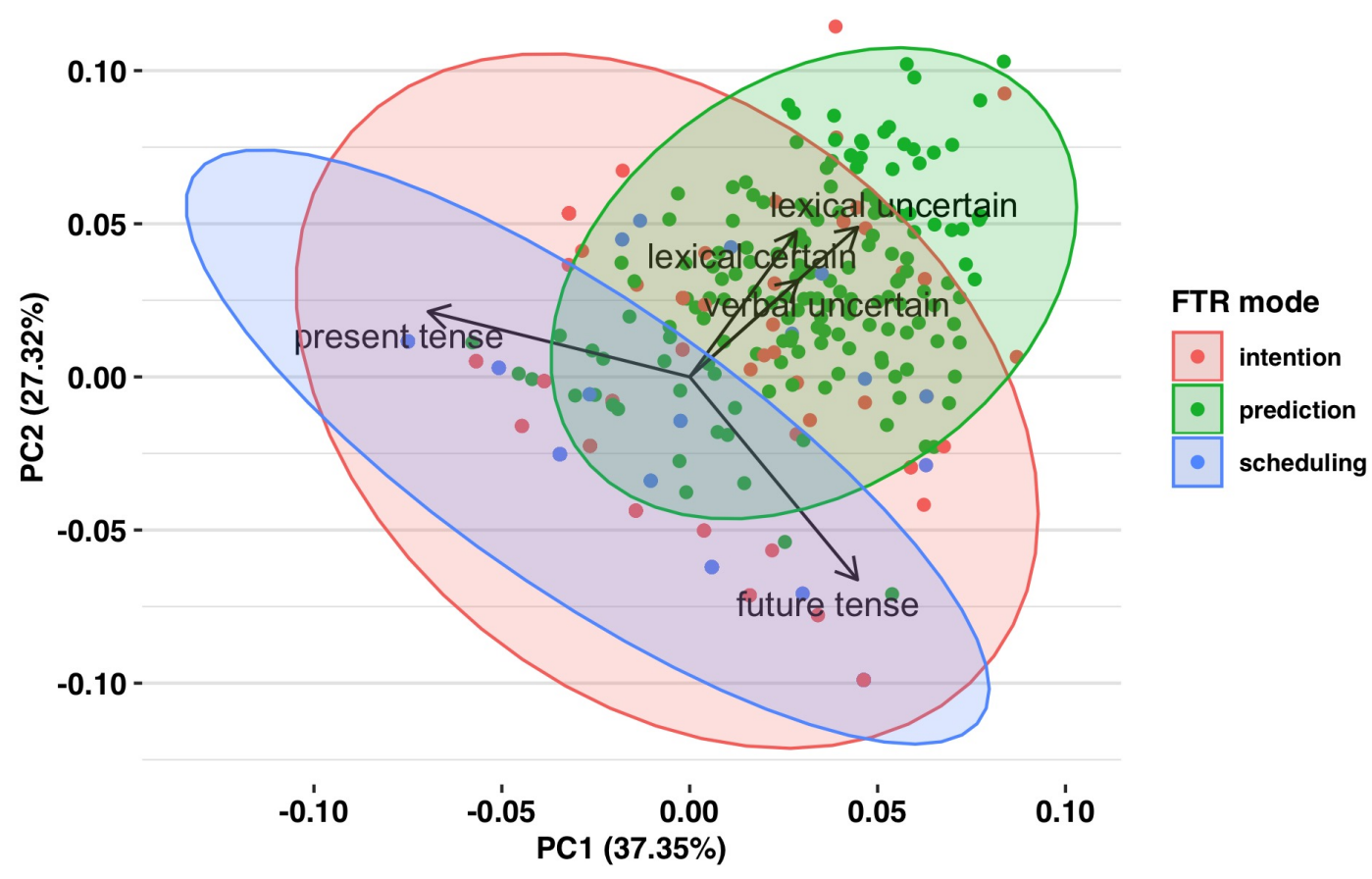

Figure 11: Plot of the German PCA results; see Figs. $\square$ for notes on interpretation. 


\section{Uncertain language over temporal distance in the neutral condition}

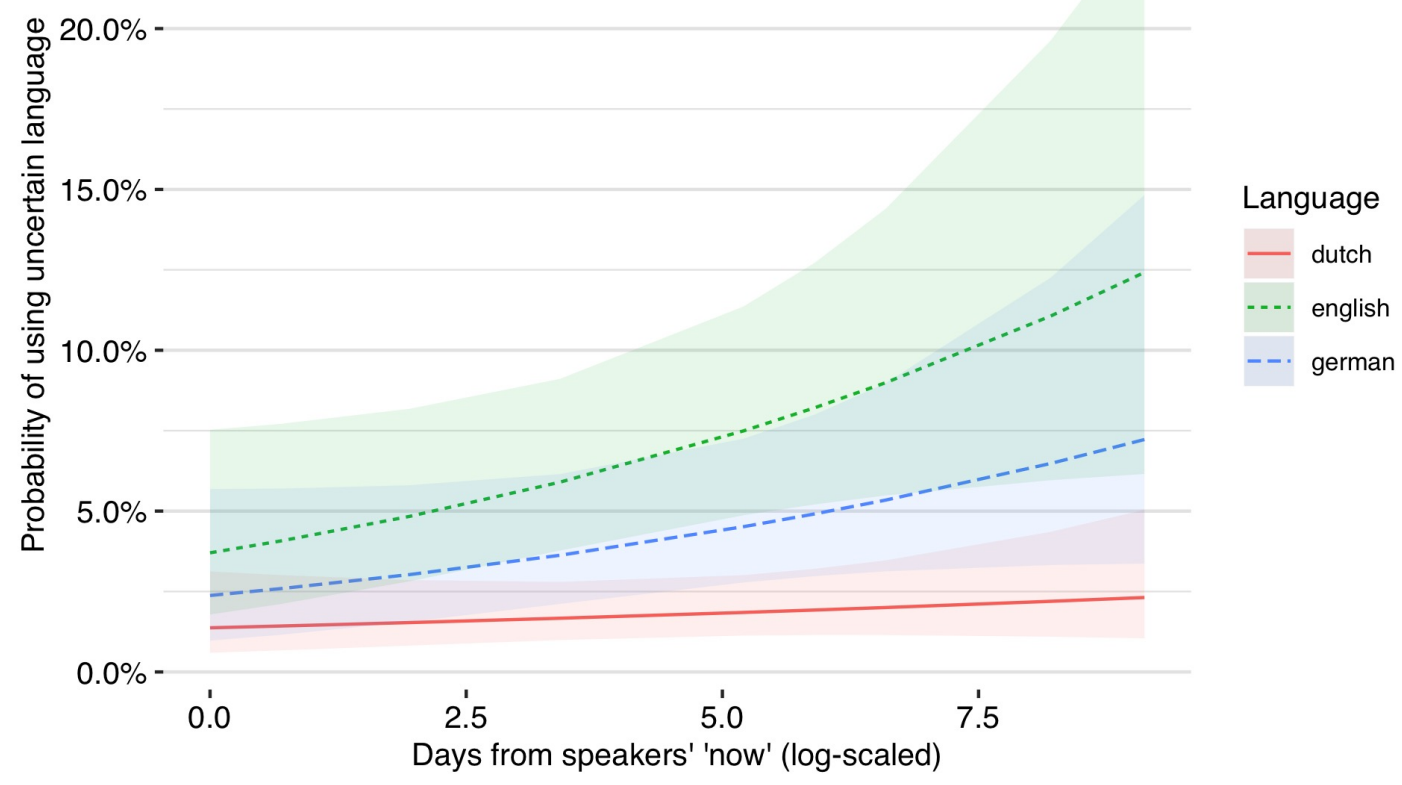

Figure 12: Plot depicts the predicted probabilities for the model reported in Table 4 in the neutral condition, and presents use of uncertain language usage as a function of language, temporal distance, and probability condition. See SM for plots of uncertain and certain conditions. 


\section{Example discounting planes}

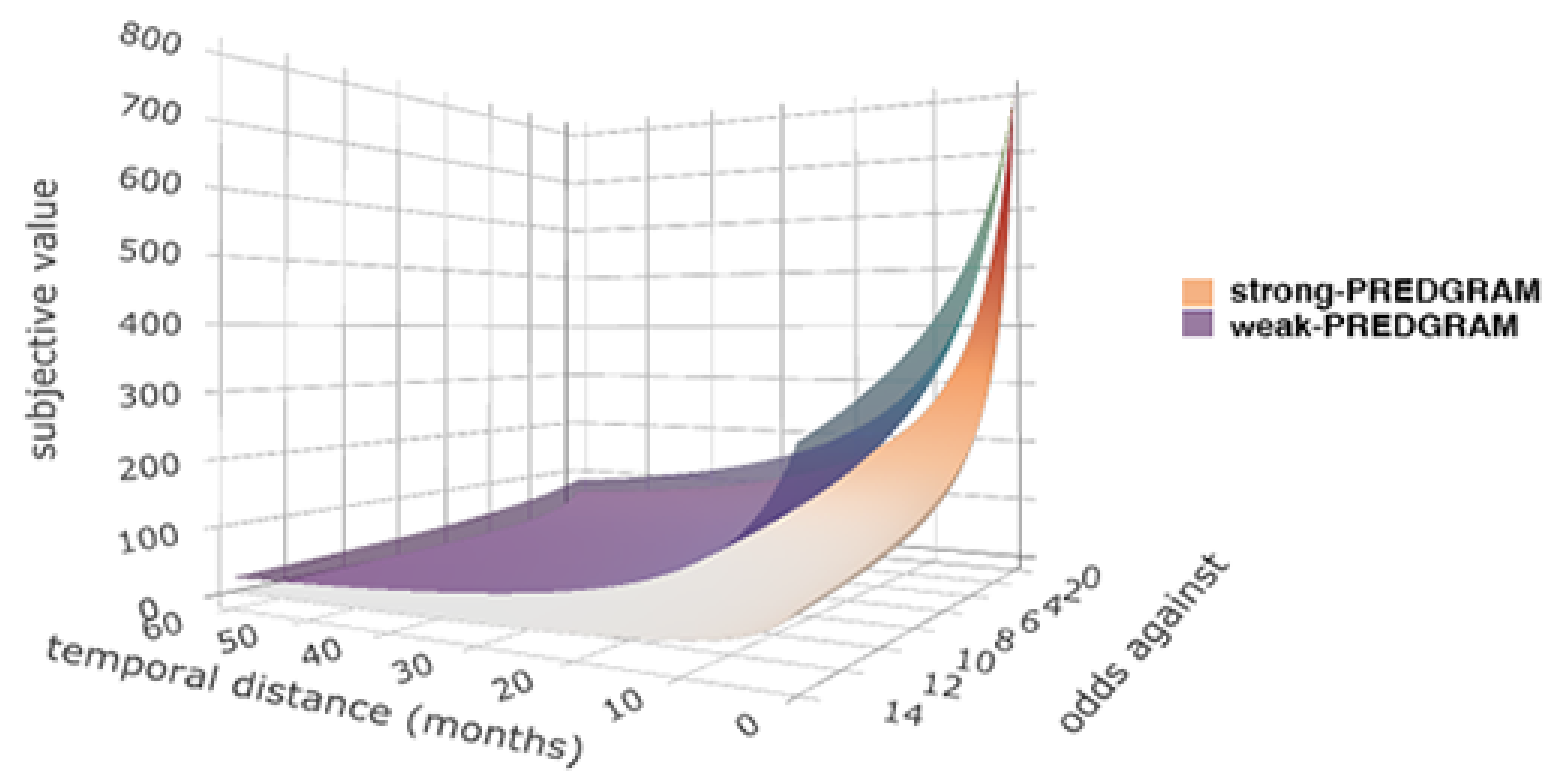

Figure 13: Plot depicts examples of differently shaped discounting planes. Two planes represent hypothetical discounting functions for someone who speaks a language which strongly grammaticizes prediction (lower plane, steeper discounting), and someone who speaks a language which doesn't (higher plane less discounting). Planes are created by adjusting values of $k$ and $h$ (with all else is held constant) in equation 1 from 0.218 and 0.731 "strong-PREDGRAM" to 0.15 and 0.15 "weak-PREDGRAM", respectively. Weak stochastically dominates strong. However, plot is illustrative only. In reality, our results indicate that differences in the grammaticization of prediction are likely to be continuous not dichotomous. Additionally, this plot depicts differences in subjective value as a function of changes in scaling parameters in a stable time and probability space. It may also be the case the cross-linguistic differences in the grammaticization of prediction give rise to differences in beliefs about relative probability and temporal distance, as is depicted regarding temporal distance in Figs. $1=2$ 


\section{Acknowledgments}

We thank Elise Hamerslag, Saskia van Putten, Josje de Valk, Birgit Rauchbaur, Max van Duijn, Gabriela Jank, and Mary Kempnich for providing excellent translations, and Hilário de Sousa, Leonard Michaels, and Bronwyn Tarr for coding sentences to test the FTR-classifier against. We also thank Peter Hamerslag for coding work, as well as Dutch copy editing and advice, and Asifa Majid and Robin Dunbar for editing and advice on manuscript structure. SR is supported by a Leverhulme early career fellowship (ECF2016-435), and CR is supported by a Natural Sciences and Engineering Council of Canada doctoral fellowship (PGSD2 - 517110 - 2018). We also wish to acknowledge the support of the EU's Horizon 2020 FET Open RIA 662725 IBSEN project. 


\section{References}

Aguinis, H., Gottfredson, R., \& Culpepper, S. (2013). Best-Practice Recommendations for Estimating Cross-Level Interaction Effects Using Multilevel Modeling. Journal of Management, 39(6), 1490-1528. doi: 10.1177/0149206313478188

Angeletos, G. M., Laibson, D., Repetto, A., Tobacman, J., \& Weinberg, S. (2001). The hyoerbolic consumption model: Calibration, simulation, empirical evaluation. Journal of Economic Perspectives, 15, 47-68.

Antuñano, I. I. (2008). Path Salience in Motion Events. In J. Guo, E. Lieven, N. Budwig, S. Ervin-tripp, \& K. Nakamura (Eds.), Crosslinguistic approaches to the psychology of language: Research in the tradition of dan isaac slobin (pp. 403-414). New York: Psychology Press.

Auwera, J. V. D., \& Plungian, V. A. (1998). Modality's semantic map. Linguistic Typology, 2, 79-124. doi: 10.1515/lity.1998.2.1.79

Baucells, M., \& Heukamp, F. (2010). Common ratio using delay. Theory and Decision, 68(1-2), 149-158. doi: 10.1007/s11238-008-9130-2

Baucells, M., \& Heukamp, F. (2012). Probability and time trade-off. Management Science, 58(4), 831-842. doi: 10.1287/mnsc.1110.1450

Białaszek, W., Ostaszewski, P., Green, L., \& Myerson, J. (2019). On Four Types of Devaluation of Outcomes Due to Their Costs: Delay, Probability, Effort, and Social Discounting. The Psychological Record, 69, 415-424. doi: 10.1007/s40732-019 $-00340-\mathrm{x}$

Boroditsky, L. (2006). Linguistic Relativity. In L. Nadel (Ed.), Encyclopedia of cognitive science (pp. 917-921). Hoboken: John Wiley \& Sons, Ltd.

Bouma, L. (1973). The Semantics of The Modal Auxiliaries In Contemporary German. 
The Hague: Moulten.

Bouma, L. (1975). On contrasting the semantics of the modal auxiliaries of German and English. Lingua, 37, 313-339.

Broekhuis, H., \& Verkuyl, H. J. (2014). Binary tense and modality. Natural Language and Linguistic Theory, 32(3), 973-1009. doi: 10.1007/s11049-013-9213-9

Bross, F. (2012). Modal particles and the common ground. Helikon. A Multidisciplinary Online Journal, 2, 182-209. doi: 10.1075/pbns.114.19kar

Bybee, J., \& Dahl, Ö. (1989). The creation of tense and aspect systems in the languages of the world. Studies in Language, 13(1), 51-103.

Bybee, J., Perkins, R., \& Pagliuca, W. (1994). The Evolution of Grammar. Chicago: University of Chicago Press.

Byloo, P., Kastein, R., \& Nuyts, J. (2006). On certainly and zeker. Belgian Journal of Linguistics, 20(1), 45-72. doi: 10.1075/bjl.20.05byl

Chen, K. (2013). The effect of language on economic behavior: Evidence from savings rates, health behaviors, and retirement assets. American Economic Review, $103(2)$, 690-731. doi: 10.1257/aer.103.2.690

Chen, S., Cronqvist, H., Ni, S., \& Zhang, F. (2017). Languages and corporate savings behavior. Journal of Corporate Finance, 46, 320-341. doi: 10.1016/j.jcorpfin.2017 .07 .009

Chen, S., Cronqvist, H., Ni, S. X., \& Zhang, F. F. (2015). Language and Corporate Decision-Making. SSRN Electronic Journal. Retrieved from http://www.ssrn . com/abstract $=2556061$ doi: $10.2139 / \operatorname{ssrn} .2556061$

Chi, J. D., Su, X., Tang, Y., \& Xu, B. (2018). Is Language an Economic Institution? Evidence from R\&D Investment. SSRN Electronic Journal. doi: http://dx.doi.org/ 
$10.2139 / \operatorname{ssrn} .3262822$

Dahl, Ö. (1985). Tense and Aspect Systems. Oxford: Blackwell.

Dahl, Ö. (2000). The Grammar of Future Time Reference in European Languages. In Ö. Dahl (Ed.), Tense and aspect in the languages of europe (pp. 309-328). Berlin/New York: Mouton de Gruyter.

Dahl, Ö. (2013). Stuck in the futureless zone. Diversity Linguistics Comment. Retrieved from https://dlc.hypotheses.org/360

de Haan, F. (1999). Evidentiality and epistemic modality: Setting boundaries. Southwest Journal of Linguistics, 18(1), 1-34.

Donaldson, B. (2017). Dutch: A Comprehensive Grammar. Abingdon: Routledge.

Du, W., Green, L., \& Myerson, J. (2002). Cross-cultural comparisons of discounting delayed and probabilistic rewards. The Psychological Record, 52, 479-492.

Enç, M. (1996). Tense and modality. In S. Lappin (Ed.), The handbook of contemporary semantic theory (pp. 345-58). Oxford: Blackwell.

Evans, N., Bergqvist, H., \& San Roque, L. (2018). The grammar of engagement I: Framework and initial exemplification. Language and Cognition, 10(1), 110-140. doi: $10.1017 / \operatorname{langcog} .2017 .21$

Fasan, M., Gotti, G., Kang, T., \& Liu, Y. (2016). Language FTR and Earnings Management: International Evidence. SSRN Electronic Journal. doi: 10.2139/ Ssrn. 2763922

Fehringer, C. (2018). Internal constraints on the use of gaan versus zullen as future markers in spoken Dutch. Nederlandse Taalkunde, 22(3), 359-387. doi: 10.5117/ nedtaa2017.3.fehr

Figlio, D., Giuliano, P., Özek, U., \& Sapienza, P. (2016). Long-Term Orientation and 
Educational Performance. National Bureau of Economic Research Working Paper Series, 22541(10147). doi: 10.3386/w22541

Frahling, G. (2017). Linguee German English Dictionary. Köln: DeepL GmbH.

Fries, C. C. (2006). The expression of the future. Language Learning, 7(3-4), 125-133.

Galor, O., Özak, Ö., \& Sarid, A. (2016). Geographical Origins and Economic Consequences of Language Structures. IZA Discussion Paper Series(10379).

Giannakidou, A. (2014). The futurity of the present and the modality of the future : a commentary on Broekhuis and Verkuyl. Natural Language and Linguistic Theory, 32, 1011-1032. doi: 10.1007/s11049-014-9234-z

Giannakidou, A., \& Mari, A. (2018). A unified analysis of the future as epistemic modality: the view from Greek and Italian. Natural Language and Linguistic Theory, $36(1), 85-129$.

Green, L., \& Myerson, J. (2004). A Discounting Framework for Choice With Delayed and Probabilistic Rewards. Psychological Bulletin, 130(5), 769-792. doi: 10.1037/ 0033-2909.130.5.769

Green, L., Myerson, J., \& Ostaszewski, P. (1999). Amount of Reward Has Opposite Effects on the Discounting of Delayed and Probabalistic Outcomes. Joural of Experimental Psychology: Learning, Memory, and Cognition, 25(2), 418-427.

Green, L., Myerson, J., \& Vanderveldt, A. (2014). Delay and Probability Discounting. The Wiley Blackwell Handbook of Operant and Classical Conditioning, 307-337. doi: 10.1002/9781118468135.ch13

Guin, B. (2017). Culture and Household Saving. European Central Bank Working Paper Series(2069).

Gutzmann, D. (2009). Hybrid semantics for modal particles. Sprache und Datenverar- 
beitung, 33(1-2), 45-59.

Hayes, A. (2013). Introduction to Mediation, Moderation, and Conditional Process Analysis. New York: The Guilford Press.

Hogeweg, L., Ramachers, S., \& Wottrich, V. (2011). Doch, toch, and wel on the table. Linguistics in the Netherlands, 28(2007), 50-60. doi: 10.1075/avt.28.05hog

Hübner, M., \& Vannoorenberghe, G. (2015a). Patience and Inflation. Munich Personal RePEc Archive(65811). doi: 10.1227/01.NEU.0000349921.14519.2A

Hübner, M., \& Vannoorenberghe, G. (2015b). Patience and long-run growth. Economics Letters, 137, 163-167. doi: 10.1016/j.econlet.2015.10.011

Huddleston, R. (1995). The case against a future tense in English. Studies in Language, $19(2), 399-446$.

Huddleston, R., \& Pullum, G. K. (2002). The Cambrige Grammar of the English Language. Cambridge: Cambridge University Press.

Huitink, J. (2008). Modals, Conditionals and Compositionality (Unpublished doctoral dissertation). Radboud.

Huitink, J. (2012). Modal concord: A case study of dutch. Journal of Semantics, 29(3), 403-437. doi: 10.1093/jos/ffr012

Janssen, T. (1989). Die Hilfsverben werden (Deutsch) und zullen (Niederländisch): modal oder temporal? In W. Abraham \& T. Janssen (Eds.), Tempus-aspekt-modus. die lexikalischen und grammatischen formen in den germanischen sprachen (pp. 65-84). Tübingen: Neimeyer.

Karagjosova, E. (2004). The Meaning and Function of German Modal Particles (Unpublished doctoral dissertation). Saarland University.

Karapandza, R. (2016). Stock returns and future tense language in 10-K reports. Journal 
of Banking and Finance, 71, 50-61. doi: 10.1016/j.jbankfin.2016.04.025

Kempnich, M. (2016). Personal Communication to Cole Robertson.

Kim, J., Kim, Y., \& Zhou, J. (2017). Languages and earnings management. Journal of Accounting and Economics, 63(2-3), 288-306. doi: 10.1016/j.jacceco.2017.04.001

Kirsner, R. S. (1969). The role of zullen in the grammar of modern standard Dutch. Lingua, 24, 101-154. doi: 10.1016/0024-3841(70)90070-7

Kissine, M. (2008). Why will is not a modal. Natural Language Semantics, 16(2), 129-155. doi: 10.1007/s11050-008-9028-0

Krippendorff, K. (1970). Estimating the reliability, systematic error and random error of interval data. Educational and Psychological Measurement, 30, 61-70.

Krippendorff, K., \& Hayes, A. (2007). Answering the call for a standard reliability measure for coding data. Communication methods and measures, 1(1), 77-89.

Kutylowski, J. (2019). Linguee Dutch English Dictionary. Köln: DeepL GmbH.

Landis, R., \& Koch, G. (1977). The measurement of observer agreement for categorical data. Biometrics, 33(1), 159-174. doi: 10.2307/2529310

Lee, A. V. D. (2016). Cultural differences in the use of epistemic modality in the European Parliament (Unpublished doctoral dissertation). Radboud.

Legler, J., \& Roback, P. (2019). Generalized Linear Models and Multilevel Models. Boston: Bookdown.

Liang, H., Marquis, C., Renneboog, L., \& Sun, S. L. (2018). Future-Time Framing: The Effect of Language on Corporate Future Orientation. Organization Science, Articles in Advance. doi: 10.1287/orsc.2018.1217

Liberman, M. (2012). Cultural diffusion and the Whorfian hypothesis. Language Log. Retrieved from http://languagelog.ldc.upenn . edu/nll/?p=3764 
Luckman, A., Donkin, C., \& Newell, B. R. (2018). Can a single model account for both risky choices and inter-temporal choices? Testing the assumptions underlying models of risky inter-temporal choice. Psychonomic Bulletin and Review, 25(2), 785-792. doi: 10.3758/s13423-017-1330-8

Lucy, J. A. (1997). Linguistic Relativity. Annual Review of Anthropology, 26, 291-312.

Lucy, J. A. (2016). Recent Advances in the Study of Linguistic Relativity in Historical Context: A Critical Assessment. Language Learning, 66 (3), 487-515. doi: 10.1111/ lang.12195

Lüdecke, D. (2019). Create Tidy Data Frames of Marginal Effects for 'ggplot' from Model Outputs.

Majid, A. (2018). Language and Cognition. In H. Callan (Ed.), The international encyclopedia of anthropology. Hoboken: John Wiley \& Sons, Ltd. doi: 10.1002/ 9781118924396.wbiea2364

Majstro. (2017). Multilingual Translation Dictionary. Retrieved 2017-06-15, from http://www.majstro.com/dictionaries/

Mavisakalyan, A., Tarverdi, Y., \& Weber, C. (2018). Talking in the present, caring for the future: Language and environment. Journal of Comparative Economics, 46(4), 1370-1387. doi: 10.1016/j.jce.2018.01.003

Mavisakalyan, A., \& Weber, C. (2018). Linguistic Structures and Economic Outcomes. Journal of Economic Surveys, 32(3), 916-939. doi: 10.1111/joes.12247

McKerchar, T. L., \& Renda, C. R. (2012). Delay and probability discounting in humans: An overview. Psychological Record, 62(4), 817-834. doi: 10.1007/BF03395837

Mindt, D. (1995). An Emprical Grammar of the English Verb: Modal Verbs. Berlin: Cornelson Verlag. 
Mortelmans, T. (2000). Konjunktiv II and Epistemic Modals in German. In A. Foolen \& F. V. D. Leek (Eds.), Constuctions in cognitive linguistics: Selected papers from the fifth international cognitive linguistics conference (pp. 191-215). Amsterdam: John Benjamins. doi: 10.1075/cilt.178.12mor

Mortelmans, T. (2009). Modal verbs, modal adverbs, and modal particals in English, German and Dutch: What markers of epistemic necessity and inferential evidentiality might express. In Modality at work. Lisbon.

Nuyts, J. (2000). Epistemic Modality, Language, and Conceptualization. Amsterdam: John Benjamins. doi: 10.1075/hcp.5

Nuyts, J., \& Vonk, W. (1999). Epistemic modality and focus in Dutch. Linguistics, 37(4), 699. doi: 10.1515/ling.37.4.699

Oxford English Dictionary. (2017). Oxford: Oxford University Press.

Palmer, R. F. (2001). Mood and modality (2nd ed.). Cambridge: Cambridge University Press.

Pearl, J., \& Mackenzie, D. (2018). The book of why (1st ed.). London: Alen Lane.

Pereltsvaig, A. (2011). You save what you speak? Languages of the World. Retrieved from https: //www. languages of theworld.info

Pérez, E. O., \& Tavits, M. (2017). Language Shapes People's Time Perspective and Support for Future-Oriented Policies. American Journal of Political Science, 00(0), 1-13. doi: 10.1111/ajps. 12290

Pullum, G. K. (2012). Keith Chen, Whorfian economist. Retrieved 2017-04-28, from http://languagelog.ldc.upenn.edu/nll/?p=3756

Python Software Foundation. (2017). Python Language Reference. Retrieved from http://www.python.org 
Rachlin, H., Raineri, A., \& Cross, D. (1991). Subjective probability and delay. Journal of the experimental analysis of behavior, 55(2), 233-44. doi: 10.1901/jeab.1991.55 $-233$

Rau, J. (2011). Semantic and Syntactic Differences between Finite and Infinitival Complements in German (Unpublished PhD Dissertation). Tübingen.

Raudenbush, S., \& Bryk, A. (2002). Hierarchical linear models: applications and data analysis and methods. London: Sage.

Roberts, S., Winters, J., \& Chen, K. (2015). Future tense and economic decisions: Controlling for cultural evolution. PLoS ONE, 10(7), 1-46. doi: 10.1371/journal .pone.0132145

Salkie, R. (2010). Will: tense or modal or both? English Language and Linguistics, 14(2), 187-215. doi: 10.1017/S1360674310000055

Sarkar, A. (1998). The Conflict Between Future Tense and Modality : The Case of Will in English. Current work in Linguistics, 5(2).

Shepherd, J., Rossner, R., \& Taylor, J. (1984). Ways to Grammar. London: Macmillan.

Simon-Vandenbergen, A.-M., \& Aijmer, K. (2007). The Semantic Field of Modal Certainty: A Corpus-Based Study of Modal Adverbs. Berlin: de Gruyter.

Slobin, D. (2006). What makes manner of motion salient? Explorations in linguistic typology, discourse, and cognition. In M. Hickman \& S. Robert (Eds.), Space in languages linguistic systems and cognitive categories (pp. 59-81). Amsterdam: John Benjamins.

Stevens, C. M. (1995). On the Grammaticalization of German können, dürfen, sollen, mögen, müssen, and wollen. American Journal of Germanic Linguistics \& Literatures, 7(2), 179-206. doi: 10.1017/S1040820700001591 
Sutter, M., Angerer, S., Glätzle-rützler, D., \& Lergetporer, P. (2015). The Effect of Language on Economic Behavior : Experimental Evidence from Children's Intertemporal Choices. Institute for the Study of Labor Discussion Paper Series(9383).

Tabachnick, B. G., \& Fidell, L. S. (2007). Using Multivariate Statistics (Vol. 28). doi: $10.1037 / 022267$

Teich, E. (2003). Cross-Linguistic Variation in System and Text. Berlin/New York: Mouton de Gruyter.

Thieroff, R. (2010). Mood in German. In B. Rothstein \& R. Thieroff (Eds.), Mood in the languages of europe (pp. 133-154). Amsterdam: John Benjamins. doi: 10.1075/slcs.120.08thi

Thoma, D., \& Tytus, A. E. (2018). How Cross-Linguistic Differences in the Grammaticalization of Future Time Reference Influence Intertemporal Choices. Cognitive Science, 42(3), 974-1000. doi: 10.1111/cogs.12525

Twisk, J. (2006). Applied multilevel analysis: A practical guide. Cambridge: Cambridge University Press.

Vanderveldt, A., Green, L., \& Myerson, J. (2015). Discounting of monetary rewards that are both delayed and probabilistic: Delay and probability combine multiplicatively, not additively. Journal of Experimental Psychology: Learning Memory and Cognition, 41(1), 148-162. doi: 10.1037/xlm0000029

Vanderveldt, A., Green, L., \& Rachlin, H. (2017). Discounting by Probabilistic Waiting. Journal of Behavioral Decision Making, 30(1), 39-53. doi: 10.1002/bdm.1917

Vuchinich, R. E., \& Simpson, C. A. (1998). Hyperbolic temporal discounting in social drinkers and problem drinkers. Experimental and Clinical Psychopharmacology, 6(3), 292-305. doi: 10.1037/1064-1297.6.3.292 
Whorf, B. (1956). Language, Thought, and Reality: Selected Writings of Benjamin Lee Whorf (J. B. Carroll, Ed.). MIT Press.

Wolff, P., \& Holmes, K. J. (2011). Linguistic relativity. Wiley Interdisciplinary Reviews: Cognitive Science, 2(3), 253-265. doi: 10.1002/wcs.104

Yi, R., de la Piedad, X., \& Bickel, W. K. (2006). The combined effects of delay and probability in discounting. Behavioural Processes, 73(2), 149-155. doi: 10.1016/ j.beproc.2006.05.001

Zimmermann, M. (2019). Discourse particles. Semantics, 2, 2011-2038. doi: 10.1515/ $9783110589863-015$ 